\title{
Recalibrating Immunity in Cancer and Autoimmune Inflammation by Galectin-1-Driven Regulatory Circuits
}

\author{
Camila A. Bach*, Anabela M. Cutine*, Lorena Laporte*, Yamil D. Mahmoud*, \\ Montana N. Manselle Cocco*, Mora Massaro*, Joaquín P. Merlo*, Ramiro M. \\ Perrotta*, Nicolas Sarbia*, Florencia Veigas* and Gabriel A. Rabinovich**
}

Laboratorios de Inmunopatología, Glicómica Funcional e Inmuno Oncología Translacional, Instituto de Biología y Medicina Experimental (IBYME), Consejo Nacional de Investigaciones Científicas y Técnicas (CONICET), Buenos Aires, Argentina.

* These authors contributed equally to this work.

${ }^{* \star}$ Corresponding author. E-mail: gabyrabi@gmail.com

\begin{abstract}
Endogenous lectins play key roles in cell homeostasis by decoding the information encrypted in glycans present on the cell surface or extracellular matrix. Galectins, a family of soluble lectins, have emerged as central regulators of innate and adaptive immune responses. In this article, we review seminal work demonstrating the immunoregulatory roles of Galectin-1 (Gal-1), a proto-type member of the galectin family, and highlight central mechanisms that control its functions in cancer and autoimmune inflammation. Understanding the cellular pathways that control Gal-1 expression

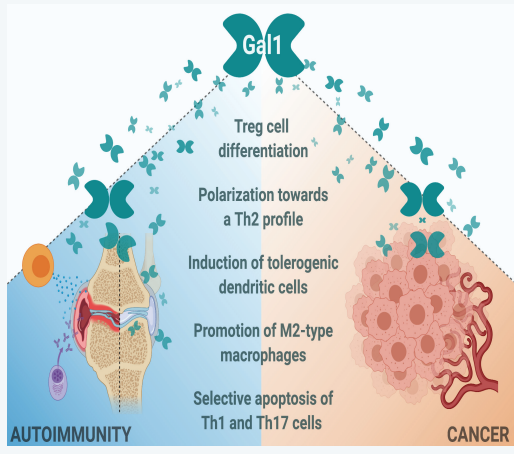
and function in tumor and inflammatory microenvironments will set the bases for the design of rational therapies based on positive or negative modulation of this endogenous lectin in cancer and autoimmune diseases.
\end{abstract}

\section{Keywords:}

galectins, immunomodulation, cancer, metastasis, inflammation, autoimmunity

\section{Introduction: The cellular glycome}

Every cell, from bacteria to neurons or lymphocytes, displays saccharide structures (glycans) covalently linked to proteins and lipids on the cellular surface. Glycans play crucial roles in several biological processes, such as cellular migration, differentiation, communication, immunity, and vascularization [1-4]. Our immune system harnesses the vast amount of information stored in glycan structures to control its activation, differentiation, and homeostasis [5]. Glycans are hierarchically assembled in proteins and lipids through the coordinated action of glycosyltransferases and glycosidases. In mammals, protein glycosylation occurs in parallel to protein synthesis in the endoplasmic reticulum, and then continues in the Golgi apparatus. To decipher the information encoded by glycoconjugates, dedicated glycan-binding proteins are required, which trigger distinct signaling pathways to modulate cell fate and function.

In the era of multi-omics, "glycomics" arises as a major challenge being tackled by scientists from different backgrounds and disciplines. Studying the structure, functions, and synthesis of lectins and glycans is the main goal of Glycobiology. Due to the high combinatorial possibilities of glycans present in cells and tissues, these structures emerge as a major source of biological information and diversity. This feature makes glycoconjugates attractive therapeutic targets and biomarkers in several pathologic conditions. First, their location on the cell surface makes them the first 
contact point during cellular communication, thus operating as central regulators of a diversity of metabolic processes and host-pathogen interactions [6]. Second, specific glycan structures that are absent or are present in very low amounts in steady-state conditions can increase in proportion or alter their composition under stress or pathologic situations. Finally, lectin-glycan interactions may trigger, aggravate, or ameliorate pathological conditions by recalibrating immune cell homeostasis and rewiring signaling pathways in several cell types.

\section{Glycosylation pathways and glycan-binding proteins}

There are two major glycosylation pathways, namely $N$ - and $O$-glycosylation (Figure 1 ). The prevalence of each individual pathway relies on several factors, including cell type and its physiologic activation, differentiation, and nutritional state. Furthermore, epigenetic regulation of glycosyltransferases and glycosidases, subcellular compartmentalization of individual components of the glycosylation machinery and nucleotidic sugar availability are also critical factors that affect the abundance of different glycans [7]. The presence of $N$ - and $O$-glycans on a given cell type also depends on dynamic parameters of individual microenvironments including the oxygen levels, nutrient availability and prevalence of particular growth factors and cytokines. In this regard, a complex interplay occurs between the glycosylation profile of a given cell type and the development of particular disease states, highlighting the importance of studying the cellular glycome under physiologic and pathologic conditions [1]. In fact, particular glycosylation profiles have been associated with pathologic processes including chronic inflammation [8-10] and cancer [11,12].

The myriad of possible glycan combinations that can arise as a consequence of the coordinated action of glycosyltransferases and glycosidases has been shown to provide a valuable source of information that governs cell processes, including proliferation, survival, activation, differentiation, and migration [1]. $N$-glycosylation involves the addition of glycans on an asparagine residue within a consensus region -N-X-S/T, where X cannot be proline. This process involves sequential modification of an initial mannose-rich glycan by glycosidases and glycosyltransferases. Of particular interest for this review are $N$-acetylglucosaminyltransferases (MGAT1, 2, 4, and 5) that play critical roles as they generate the $N$-acetylglucosaminyl branches that serve as permissive sites for further extension of $N$-acetyl-lactosamine (Gal $\beta 1$ 4GlcNAc; LacNAc) structures, which are the main target for galectins [13,14]. Furthermore, $\alpha 2,6$-sialyltransferase 1 (ST6Gal-1), an enzyme that incorporates sialic acid to complex $N$-glycans in an $\alpha 2,6$-linked position, inhibits binding of specific galectins (particularly Gal-1) to $N$-glycan structures. On the other hand, $O$-glycosylation occurs later, inside the Golgi apparatus, on serine or threonine residues, with T-synthase (C1GALT1) being critical for the formation of core1 - $O$-glycans and $\alpha 2,3$-sialyltransferase (ST3Gal-1) further adding sialic acid to the galactose residue within the same structure [4]. 


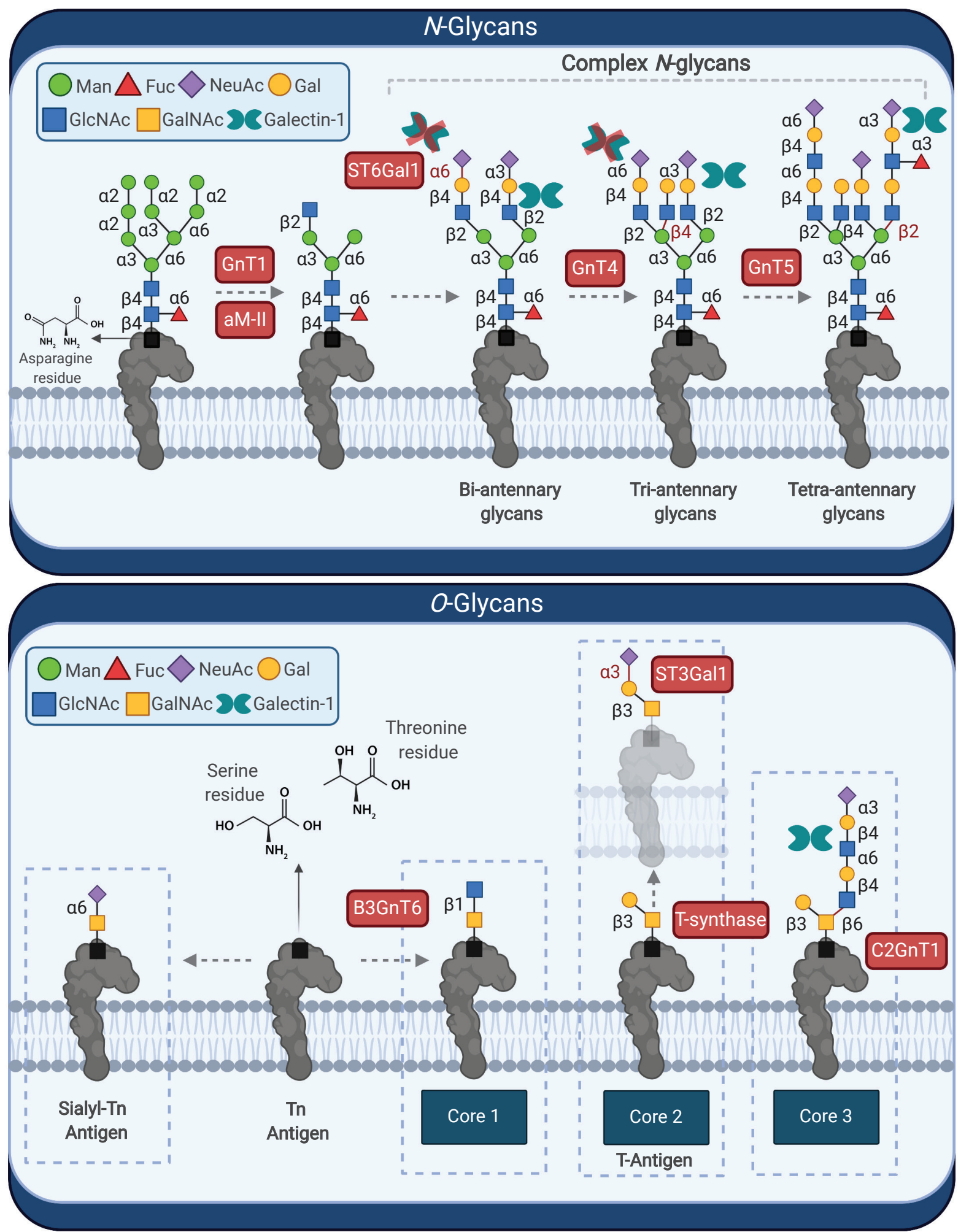

Figure 1. Glycosylation pathways involved in the synthesis of galectin ligands. The figure shows a summary of the main protein glycosylation pathways: $\mathrm{N}$ - and $\mathrm{O}$-glycosylation and Gal-1 binding sites. Created with BioRender.com.

The responsibility of decoding the biologic information encrypted by glycans relies on endogenous glycan-binding proteins or lectins. Lectins are capable of recognizing complex glycosidic structures attached to proteins and lipids on the cell surface, triggering different cellular responses. The magnitude and quality of these responses ultimately rely on the multivalent nature of lectin-glycan interactions $[15,16]$. Several studies have shown, using computational modeling and biophysical approaches, that lectin-glycan interactions can lead to the formation of complex multivalent structures, 
often termed "lattices", on the surface of different cell types [16]. These structures may be assembled into supramolecular domains on the cell surface leading to glycoprotein segregation and control of signaling threshold, activation and endocytosis of cell surface receptors [17]. In several cases, these lectin-glycan complexes may substitute canonical ligands and activate surface receptors, triggering vital biologic responses such as activation, differentiation and survival [18]. Within the immune system, three major families of lectins play crucial stimulatory or inhibitory roles: a) C-type lectin receptors (CLRs); b) Sialic acid-binding immunoglobulin-type lectins (Siglecs) and c) galectins [9,10,12].

CLRs comprise a heterogeneous family of calcium ion-dependent lectins subdivided into two distinct categories based on the presence of an amino acid motif involved in glycan recognition and calcium coordination. Most of these lectins possess one or more carbohydrate recognition domains (CRDs) and are present on the surface of many immune cell types, such as macrophages and dendritic cells (DCs). CLRs containing the amino acid motif EPN (Glu-Pro-Asn) have an affinity for glycans containing mannose or fucose. This subgroup includes DC-Specific Intercellular adhesion molecule3-Grabbing Non-integrin (DC-SIGN), the mannose receptor (MR), and Langerin. The other is composed of CLRs containing the QPD motif (Gln-Pro-Asp), which interacts specifically with $N$-acetyl-galactosamine present in the terminal position of glycans. MGL receptor (Macrophage Galactose-type Lectin), present in macrophages and DCs, is an example of this subgroup of CRLs [19]. It is worth mentioning that some CLRs do not have the $\mathrm{Ca}^{2+}$ requirement to interact with glycans, such as the Dectin-1 receptor that specifically recognizes $\beta$-glucans in yeasts [20]. The interaction between many specific CLRs and glycans leads to ligand internalization by endocytosis, followed by intracellular signaling pathways that lead to the expression of innate immunity-related genes [21]. Thus, CLRs are key lectins that participate in the innate immune response to bacterial and fungal infections, among other functions.

Siglecs are a family of lectins that have specificity for glycans containing sialic acid. Some of them have a restricted expression pattern, such as Siglec-2 (CD22) that is preferentially found on B cells, while others are expressed in several hematopoietic lineage cells, like B lymphocytes, macrophages, and eosinophils. To date, 16 Siglecs have been identified in humans, showing a variable number of immunoglobulin-like domains ranging from 2 in Siglec-3 (CD33) to 17 in Siglec-1 (Sialoadhesin, CD169) and slight differences in sialoside preferences. Several members of this family are relevant in many infectious diseases (e.g. HIV-1 and Group B Streptococcus infections), autoimmune diseases (e.g. rheumatoid arthritis), cancer (e.g. leukemia, lymphoma) and neurological diseases (e.g. Alzheimer disease) [6]. Recognition of sialic acid by siglecs usually promotes phosphorylation of the cytoplasmic ITIM motifs and further recruitment of phosphatases from the SHP family, which in turn inhibit diverse cell events including activation, signaling and proliferation [22].

While CLRs and siglecs act primarily as transmembrane proteins present on the surface of immune cells, galectins are soluble proteins secreted into the extracellular medium via a non-canonical secretory pathway (without involvement of the ER-Golgi system). Once in the extracellular space, galectins interact with a wide variety of glycosylated receptors through protein-glycan and protein-protein interactions, in a broad spectrum of cell types [10,12]. Intracellularly, galectins can modulate signaling pathways, control lymphocyte survival, and even interact with the RNA splicing machinery [10,2326]. Fifteen members of the galectin family are known in mammals, although galectin-like domains have been identified in insects, fungi and plants [25, 27]. Galectins have at least one CRD of approximately 130 structurally-preserved amino acids and can be subdivided into three subgroups based on their structural features: a) "Proto-type" galectins (Gal-1, -2, $-5,-7,-10,-11,-13,-14$, and -15) have a single CRD and can be found as monomers or dimers; b) "Tandem repeat-type" galectins (Gal-4, -6, -8, -9, and -12) contain two tandem CRDs within the same polypeptide chain, joined by a separating region (linker) of up to 70 amino acids; and c) "Chimera-type" galectins have a single CRD together with a non-lectin N-terminal region necessary for its oligomerization, with Gal-3 being the only member of this subgroup. (Figure 2) [10, $25,28]$.

Initially, galectins were defined by their ability to recognize the disaccharide LacNac present in $N$ - and $O$-glycans on cell surface glycoproteins [29]. However, galectins' CRDs can differ in some amino acids, which are not in the conserved sequence, leading to their ability to recognize different structures. Furthermore, modifications to the LacNAc or polyLacNAc structure can differentially affect galectin-glycan interactions. While some galectins tolerate the addition of a terminal sialic acid or internal fucose in the lactosamine sequence, others are not able to bind LacNac modified with these residues [30, 31]. In this regard, we have recently found that Gal-12, a lectin preferentially expressed by adipocytes, binds to 3'-fucosylated structures with high affinity, making it the first member of the galectin family showing specificity for this glycan structure [32]. Besides, galectins differ in their ability to recognize LacNAc in a terminal position or internal repetitions within the glycan structure (Figure 2). This relative selectivity could explain, at least in part, the functional differences observed among individual family members [29, 33-35]. Several factors can influence the biological activity of galectins including their oligomerization status, exposure of $N$ - and $O$-glycans on target cells and the prevailing oxidative or reducing conditions of different tissue microenvironments [10]. While some galectins have a ubiquitous expression pattern, others exhibit a specific tissue distribution. Within the immune system, galectins are expressed by virtually all cells either constitutively or in an inducible manner [10, 15, 25, 28]. Furthermore, galectins can recognize glycans present on the surface of microorganisms, suggesting an early evolutionary origin for these molecules as soluble proteins capable of recognizing pathogen-associated glycosylated patterns $[15,36,37]$. 


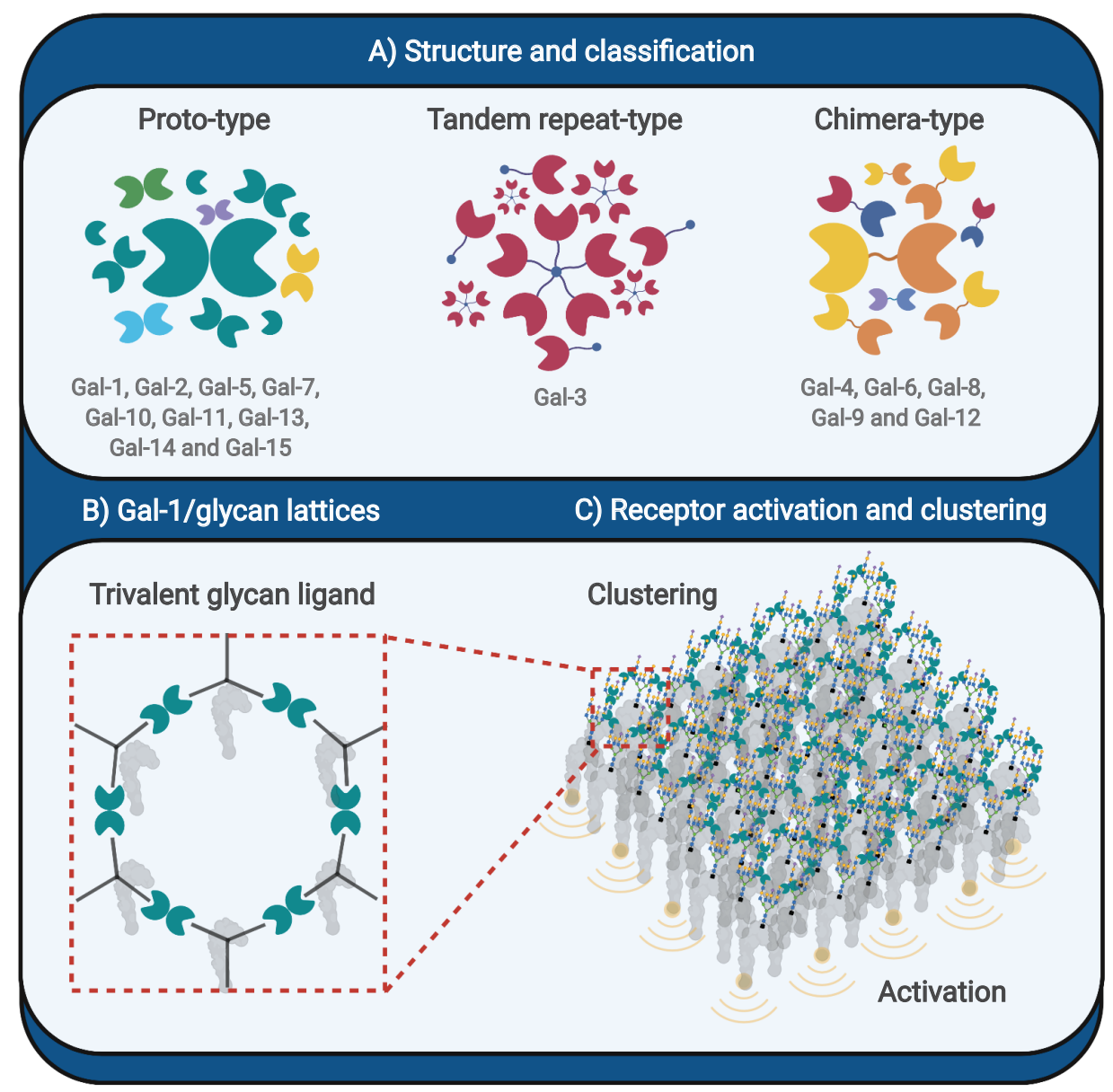

Figure 2. Classification of galectins: structure, function, and specificity. A- Schematic representation of the structure of the galectin family; B- Schematic representation of Gal-1 lattices upon trivalent glycan binding. C- Lattice formation gives rise to receptor clustering, activation triggering and altered internalization. Created with BioRender.com.

In the following sections, we will focus on seminal discoveries leading to the identification of central roles of Gal-1, crucial to immune tolerance and homeostasis in different physiopathologic conditions. We will discuss the therapeutic implications derived from the function of Gal-1 in chronic inflammation, vascularization, autoimmunity, pregnancy, and cancer, and we will highlight some of the contributions of our group to understanding these conditions from a glycobiological perspective.

\section{Gal-1: A novel mechanism of tumor-immune escape and therapeutic target in cancer}

During the last decade, the revolution of cancer immunotherapies changed our perspective on how our immune system interacts with tumors. However, the idea of the immune system playing a pivotal role in tumor biology dates back to more than a century ago when William Coley used extracts of heat-inactivated S. pyogenes and S. marcescens (termed as the Coley toxin) to treat cancer patients seeking to enhance their immune response [38, 39]. In 1909, Paul Ehrlich came up with the idea that our immune system is continuously eliminating transformed cells that could potentially cause tumors $[38,40]$. Back to our days, it is well established that a fully competent immune system, composed of a variety of cell types including natural killer (NK) cells, $\mathrm{CD}^{+}$cytotoxic $\mathrm{T}$ lymphocytes, $\mathrm{CD} 4^{+}$helper $\mathrm{T}$ lymphocytes, macrophages, DCs and others, can identify and destroy transformed cells in pre-neoplastic and neoplastic lesions. Nevertheless, either due to a generalized state of immunosuppression or to specific inhibitory mechanisms displayed within the local tumor microenvironment, cancer cells have the ability to evade innate and adaptive immune responses. In fact, many cancer cells co-opt immunoregulatory programs that are commonly activated during the physiologic resolution of inflammation to restore immune cell homeostasis. For example, the expression of Programmed Cell Death Ligand-1 (PD-L1) on 
the surface of tumor cells dampens the activation and proliferation of $\mathrm{T}$ cells, fostering a dysfunctional state called $\mathrm{T}$ cell exhaustion, which compromises cytotoxic anti-tumor immunity favoring tumor growth [38]. Among the several mechanisms implicated in immune evasion, the upregulation of inhibitory molecules termed as "immune checkpoints", such as the PD-1/PD-L1 axis and the cytotoxic T-lymphocyte antigen receptor (CTLA-4), stand out among the others due to their clinical and therapeutic relevance in a broad range of cancers [41-44].

Understanding the mechanisms underlying tumor-immune escape led to the development of a broad range of immunotherapeutic modalities seeking to reverse the immune inhibitory mechanisms triggered by tumors and boosting the immune system to control tumor growth and metastasis. In particular, monoclonal antibodies targeting the immune checkpoint pathways CTLA-4 and PD-1/PD-L1 have generated unprecedented clinical success and therapeutic opportunities to treat a wide variety of tumors including melanoma, lung adenocarcinoma, renal cancer, gastrointestinal tumors, head and neck squamous cell carcinoma (HNSCC), triple negative breast cancer, non-melanoma squamous cell carcinomas, Hodgkin's lymphoma, and others. Moreover, other therapeutic approaches are based on agonist antibodies to co-stimulatory molecules, tumor cell vaccines (like DC vaccines), or chimeric antigen receptors (CARs) [38]. Outstanding clinical benefits, including tumor size reduction and increased disease-free survival, have been observed in a large number of cancer patients receiving immunotherapy [41-45]. However, some patients are resistant to these treatments, either through intrinsic or acquired mechanisms, and experience a relapse characterized by tumor recurrence at the primary site or distant tissue outgrowth in a process known as metastasis $[45,46]$. These compensatory mechanisms include the expression of alternative inhibitory molecules such as lymphocyte activation gene-3 (LAG-3) and T cell immunoglobulin mucin-3 (TIM-3), among others, whose autonomic functions can control various aspects of the anti-tumor immune response, promoting alternative escape pathways [47].

Our laboratory has focused on elucidating the immunoregulatory circuits triggered by Gal-1-glycan interactions in tumor and inflammatory microenvironments. Initially, we found that human and mouse melanoma cells secrete Gal1, which substantially contributes to the immune privilege of these tumors by regulating distinct immune effector mechanisms. Gal-1 silencing in the B16 melanoma mouse model resulted in heightened tumor rejection, increasing expansion of $\mathrm{T}$ helper (Th1) and cytotoxic $\mathrm{CD}^{+} \mathrm{T}$ cells [48] (Figure 3). Investigation of the molecular mechanisms underlying Gal-1-driven immunoregulation revealed the ability of this lectin to induce selective apoptosis of cytotoxic $\mathrm{CD}^{+} \mathrm{T}$ cells, Th1, and Th17 lymphocytes, skipping Th2 and naive T cells $[48,49]$. This differential susceptibility to cell death was associated with dissimilar sialylation patterns among distinct effector $\mathrm{T}$ cells. Whereas activated CD $8^{+} \mathrm{T}$ cells as well as Th1, and Th17 display all of the essential glycans that are critical for Gal-1 binding (high frequency of nonsialylated glycans and elongated LacNAc residues on core-2- $O$-glycan structures), Th2 lymphocytes as well as naïve $\mathrm{T}$ cells exhibit high frequency of $\alpha 2,6$ sialylation which prevents Gal-1 binding to terminal LacNAc residues [10, 49] (Figure 3). Interestingly, this tumor-immune privilege mechanism was also evident in classical Hodgkin's lymphoma. In these tumors, Reed Sternberg cells up-regulate Gal-1 expression through the activation of an enhancer of the AP-1 transcription factor driven by the Epstein Bar virus (EBV), thereby supporting the Th2-dominant immunosuppressive microenvironment typical of this hematologic malignancy [50]. Accordingly, Gal-1 has been identified as a biomarker of refractory/resistant disease in classical Hodgkin lymphoma patients [51]. Furthermore, Gal-1 silencing in the triple negative breast cancer mouse model 4T1 resulted in reduced tumor size and metastases, accompanied by lower frequency of regulatory T cells (Treg) in the tumor microenvironment, lymph nodes and metastatic lungs [52] (Figure 3). Thus, both tumor and associated stroma may express and secrete Gal-1, promoting the generation of an immunosuppressive milieu and the activation of tolerogenic circuits that thwart the development of effective anti-tumor $\mathrm{T}$ cell responses.

In addition to modulation of adaptive T-cell responses, Gal-1 also controls innate immune pathways by modulating macrophage and DC function. In this regard, we found that Gal-1 triggers an M2 macrophage profile by regulating L-arginine metabolism and interfering with major histocompatibility complex (MHC)-II-dependent antigen presentation as well as Fc $\gamma$ receptor I-dependent phagocytosis [53, 54]. Furthermore, silencing of tumor-derived-Gal-1 by shorthairpin RNA (shRNA) in the high-grade glioma mouse model GL261 decreased myeloid cell accumulation within the tumor microenvironment and prolonged survival in tumor-bearing mice [55]. In addition, Gal-1 induced differentiation of tolerogenic DCs by regulating phosphorylation of the signal transducer and activator of transcription 3 (STAT3) transcription factor, and favoring the expression of anti-inflammatory cytokines including IL-27 and IL-10, which dampen anti-tumor responses [56]. In addition, Gal-1 secreted by mouse and human neuroblastoma cells triggers immunosuppressive programs by compromising T cell and DC functions [57] (Figure 3).

The expression of Gal-1 in several cancer types, including prostate, breast, lung and pancreatic cancer, increases with tumor progression, thus underlining a central role of this lectin as a possible prognostic biomarker of neoplastic progression and an attractive therapeutic target in a variety of cancer types [58-60]. In this context, we found that Gal1 exerts both paracrine and autocrine functions that control proliferation, anti-tumor immunity, and angiogenesis in pancreatic adenocarcinoma, thus reinforcing the multifunctional role of Gal-1 during tumor progression [60]. Supporting 
these observations, high levels of Gal-1 were associated with lower infiltration of cytotoxic $\mathrm{CD}^{+} \mathrm{T}$ cells and poor clinical outcomes in T cell lymphomas [61]. Furthermore, Nambiar and colleagues recently reported a role for Gal-1 in resistance to immunotherapy in HNSCC. Particularly, Gal-1 blockade increased T cell infiltration, leading to superior responses to anti-PD-1 therapies in this tumor type [62]. Likewise, we found that Gal-1 secretion by tumor-driven $\gamma \delta$ T cells contributes to tumor progression by linking commensal microbiota, systemic inflammation, and unremitted immunosuppression [63].

In addition to the broad immune inhibitory mechanisms, Gal-1 also contributes to tumor growth and progression by favoring the generation of tumor-associated blood vessels. We found that Gal-1 promotes vascularization through direct association with the complex $N$-glycans present on the vascular endothelial growth factor (VEGF) type 2 receptor (VEGFR2). This pro-angiogenic program is triggered under hypoxic conditions, which up-regulate Gal-1 expression in tumor cells [64] and induce changes in VEGFR2 glycosylation characterized by high frequency of complex branched $N$-glycans and low levels of $\alpha 2,6$ sialylation [65]. We found that Gal-1 blockade successfully counteracted resistance to anti-VEGF treatment by co-opting the VEGFR2 signaling pathway in different tumor models including mouse Lewis lung carcinoma and EL-4 thymic lymphoma [65]. Moreover, antibody-mediated Gal-1 neutralization promoted vessel normalization and influx of $\mathrm{CD}^{+} \mathrm{T}$ lymphocytes in different tumor types [65] (Figure 3). Interestingly, in melanoma patients treated with anti-VEGF (bevacizumab) and anti-CTLA-4 (ipilimumab), circulating Gal-1 levels are associated with a poor clinical outcome, while circulating anti-Gal-1 autoantibodies correlates with clinical response [66]. Thus, Gal1 serves as a novel glyco-checkpoint that controls immune and vascular signaling programs and an attractive therapeutic target in various cancer types including melanoma, Hodgkin lymphoma, chronic lymphocytic leukemia (CLL), Kaposi's sarcoma, lung, breast, kidney, pancreatic, and prostate carcinomas, glioblastoma and neuroblastoma [58]. Thus, Gal-1 blockade, either alone or in combination, represents a promising immune therapeutic strategy to treat advanced stage and refractory tumors.

\section{Gal-1: A key regulator of the metastatic cascade}

Metastasis is a multistage program through which cancer cells detach from the tissue of origin, migrate through blood or lymphatic circulation and colonize a secondary organ $[67,68]$. Besides serving as local regulators of immune responses, galectin-glycan interactions have emerged as key players of the metastatic cascade, influencing tumor cell migration, survival in the circulation, dissemination, and colonization of metastatic organs. Accordingly, Gal-1 can regulate cell-cell and cell-matrix interactions, a process associated with invasiveness and metastasis in several human tumor types [69]. Gal-1 also increases adhesion of cells to the extracellular matrix (ECM) by interacting with laminin and fibronectin via glycosylation-dependent mechanisms [70, 71, 72], and it promotes homotypic and heterotypic aggregation of cancer cells $[73,74]$. In oral squamous cell carcinoma (OSCC), Gal-1 expression in cancer-associated stroma correlated with poor prognosis [75] and promoted tumor invasion by up-regulating metalloproteinase (MMP)-2 and -9 and increasing the number and length of filopodia on tumor cells [76]. Additionally, Gal-1 expression is up-regulated by stromal cells in invasive breast carcinoma patients when compared with in situ carcinomas [77]. Furthermore, Gal-1 induces upregulation of mesenchymal markers and down-regulation of E-cadherin in hepatocellular carcinoma cell lines, promoting transition from epithelial morphology toward a fibroblastic mesenchymal phenotype [78]. In addition, studies in gastric cancer cells found that high Gal-1 expression levels in cancer-associated fibroblasts (CAFs) up-regulate the expression of $\beta 1$-integrin, inducing cancer cell migration and invasion [79], and promoted epithelial-to-mesenchymal transition (EMT) via the non-canonical activation of the Hedgehog pathway [80]. Moreover, in human pancreatic cancer cells, Gal-1 induced up-regulation of genes associated with migration and invasion and facilitated EMT through nuclear factor kappa B (NF- $\kappa \mathrm{B})$ transcriptional regulation, thus influencing liver metastases [60, 81]. The pro-metastatic activity of Gal-1 was also observed in metastatic castration-resistant prostate cancer cell lines, where silencing of this lectin led to inhibition of migration and invasion via suppression of Akt and androgen receptor (AR) signaling [82]. Moreover, Gal-1 has also been identified as a key effector of tropomyosin receptor kinase-mediated invasiveness and migration in human neuroblastoma cell lines [83], highlighting diverse mechanisms underlying the pro-metastatic role of this lectin in tumor microenvironments.

In addition to the extracellular roles of Gal-1, this lectin has an important intracellular role in cancer by sustaining proliferative signals through specific interactions with oncogenic RAS, a well-known cancer driver gene mutated in several tumors. Constitutive activation of HRAS, KRAS, and NRAS proteins promotes continuous proliferation in different cancer types [84]. In this setting, Gal-1 facilitates RAS membrane anchorage and activation, thereby sustaining tumor cell proliferation $[85,86]$. On the other hand, the interaction between Gal-1 and RAS in lung cancer leads to chemoresistance and tumor progression through the up-regulation of p38, cyclooxygenase-2 and extracellular regulated kinase (ERK) pathways [87]. Thus, Gal-1 association with oncogenic proteins, transcription factors, cell adhesion molecules and distinct signaling pathways can have an effect on the invasion, dissemination and colonization of cancer cells, emphasizing the relevance of Gal-1 blockade to control tumor progression and metastasis. 


\section{Gal-1: A potential therapeutic agent for autoimmune and chronic inflammatory diseases}

Autoimmune diseases include a wide range of chronic inflammatory disorders generated by the interruption of immune tolerance and homeostatic mechanisms. Both genetic and environmental factors play key roles in the development of autoimmune and chronic inflammatory diseases. A deeper understanding of the cellular and molecular mechanisms underlying these immune-mediated disorders could lead to the development of new and more effective immunomodulatory therapies. Through interaction with glycosylated receptors on immune cells, Gal-1 exerts broad immunoregulatory functions promoting resolution of autoimmune inflammation [88]. The mechanisms underlying Gal-1 function involve selective deletion of Th1 and Th17 cells, inhibition of pro-inflammatory cytokines, promotion of tolerogenic DCs, expansion of Tregs and induction of M2 macrophage polarization [49,88, 89].

The precise description of different mechanisms underlying the immunoregulatory effects of different members of the galectin family in autoimmune inflammation has been reviewed recently [90]. In this section, we will focus on the role of Gal-1 in regulating immune tolerance and suppressing inflammation in different models of autoimmune disease. The immunosuppressive properties of Gal-1 have been evaluated in several diseases and experimental models of chronic inflammation and autoimmunity, including experimental autoimmune encephalomyelitis (EAE) [49], collagen-induced arthritis (CIA) [91, 92], Sjögren's syndrome [93], 2,4,6-trinitrobenzene sulfonic acid (TNBS)-induced colitis [94], celiac disease [88], experimental autoimmune uveitis (EAU), experimental induced uveitis (EIU) [95, 96], experimental autoimmune diabetes [97, 98], experimental autoimmune orchitis (EAO) [99] and allergic airway inflammation [100].

\section{Multiple Sclerosis}

Multiple Sclerosis (MS) is a chronic progressive brain and spinal cord degenerative disease characterized by the demyelination and inflammation of the central nervous system (CNS) [101, 102]. Gal-1 demonstrated immunomodulatory activity on experimental autoimmune encephalomyelitis (EAE), an animal model that recapitulates many of the clinical, histopathological, and immunological manifestations of MS [103, 104]. The resulting pathology can range from acute muscular paralysis episodes to chronic recurrent neurological processes leading to a general motor disability [105]. Th1 and Th17 lymphocyte subpopulations play key pathogenic roles in the autoimmune process underlying MS and EAE $[106,107]$. It has been postulated that Th17 cells have a critical role in the initial stage of this disease, whereas IFN- $\gamma$ secreting Th1 cells are more important in later stages of autoimmune neuroinflammation [108]. In fact, myelin-specific infiltrating Th17 and Th1 cells determine where CNS inflammation occurs [109]. Brain tissue of MS patients displays an increased proportion of Th17 lymphocytes and elevated levels of IL-17A in comparison with healthy controls [106]. We studied the role of Gal-1 in EAE by immunization of mice lacking this protein $\left(\mathrm{Lgals}_{\mathrm{S}} \mathrm{F}^{-/}\right)$with myelin-oligodendrocyte glycoprotein (MOG) ${ }_{35-55}$ peptide. Lack of endogenous Gal-1 resulted in greater disease severity as compared to wildtype (WT) mice [49]. Mice devoid of Gal-1 showed a more pronounced area of demyelination in spinal cord sections, increased frequency of antigen-specific Th1 and Th17 cells in the spleen, as well as a more vigorous antigen-specific proliferative T-cell response [49]. Accordingly, EAE mice treated daily with recombinant Gal-1 (rGal-1) from day 3 to 9 after immunization showed a decrease in clinical severity score [49]. We found that Gal-1 exerts its function by limiting the frequency of antigen-specific IL-17- and IFN- $\gamma$-producing CD4 ${ }^{+} \mathrm{T}$ cells as a result of selective apoptosis due to differential glycosylation of these immune cell populations [49] (Figure 3). In addition to the ability of Gal-1 to control T cell physiology, we found that this lectin instructs DCs to differentiate toward a tolerogenic profile. Gal-1conditioned DCs acquired a regulatory signature characterized by IL-27 production and ability to induce IL-10-producing type-1 regulatory $\mathrm{T}(\mathrm{Tr} 1)$ cells [56]. Supporting these findings, Lgals $1^{-/}$mice injected with $\mathrm{MOG}_{35-55}$ showed a decrease in tolerogenic DCs and Tregs in comparison to WT mice [110]. Interestingly, a significant increase in Gal-1 expression has been reported during the peak and resolution phases of EAE [56], similar to the expression pattern documented for other inhibitory signals such as PD-L1 and its receptor PD-1 [111]. In addition, within the CNS, Gal-1 was mainly expressed by astrocytes during the resolution phase of EAE. Astrocyte-derived Gal-1 acts directly on microglia cells via interaction with core $2 \mathrm{O}$-glycans on CD45 phosphatase, changing the functional pattern of these cells from a pro-inflammatory M1 toward an anti-inflammatory M2 phenotype, which prevented inflammation-induced neurodegeneration [112] (Figure 3). Thus, Gal-1 triggers tolerogenic circuits within the CNS and peripheral lymphoid organs that control the severity of autoimmune neuroinflammation.

\section{Rheumatoid Arthritis}

Rheumatoid arthritis (RA) involves a chronic inflammation of synovial joints leading to cartilage destruction and bone erosion. Induction of autoantibodies, activation of resident fibroblasts, and expansion of activated autoreactive lymphocytes, macrophages, and plasma cells are typical hallmarks of this disease [113]. These innate and adaptive 
immune cells proliferate abnormally, invading both cartilage and bone and inducing increased levels of pro-inflammatory cytokines and MMPs that promote the activation of osteoclasts [114]. We assessed the preventive and therapeutic effects of Gal-1 in a murine model of CIA by means of gene and protein therapy strategies (Figure 3). Mice were immunized with type-II collagen to elicit cellular and humoral arthritogenic responses [115, 116]. Daily injections of recombinant Gal-1 or transfer of genetically-modified fibroblasts secreting high levels of this lectin, reduced the frequency of circulating anti-collagen immunoglobulins, particularly IgG2a in mice with CIA. The mechanism underlying this effect involved a shift toward a Th2-like profile, with decreased IFN- $\gamma$ and increased IL-5 production [91]. Further studies contributed to elucidate the role of Gal-1 in RA by showing that $\operatorname{Lgals}^{-/-}$mice had increased susceptibility to CIA, showing more vigorous T cell proliferation and augmented expression of IL-17 and IL-22 [92]. In RA patients, the concentration of Gal1 in synovial fluid decreased significantly compared to healthy controls, even though plasmatic levels were comparable [117]. Likewise, we found a decreased expression of this lectin in synovial tissue of juvenile idiopathic arthritis patients [118]. Moreover, in a local cohort of RA patients, we found considerably higher levels of serum Gal-1 correlating with systemic inflammation compared to healthy individuals [89], suggesting differences in local versus systemic regulation of this lectin during the course of the disease. Thus, Gal-1 controls arthritogenic inflammation by restoring T cell homeostasis and modulating cytokine production.

\section{Sjögren's syndrome}

Sjögren's syndrome is characterized by lymphocytic infiltration of exocrine glands and the presence of different autoantibodies. In contrast to CIA and EAE models, where mice were immunized with arthritogenic and encephalitogenic peptides, mice lacking Gal-1 or complex branched $N$-glycans developed spontaneous age-dependent sialadenitis resembling Sjögren's syndrome manifestations [93]. Lack of Gal-1 disrupted tolerogenic circuits and enhanced T cell

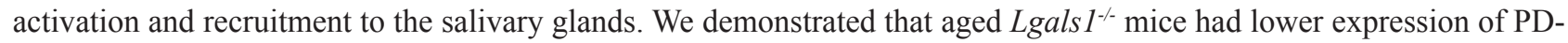
L1 in salivary gland cells and increased recruitment of IFN- $\gamma$-producing PD- $1^{+} \mathrm{CD} 8^{+} \mathrm{T}$ cells to this organ. Moreover, Gal-1-deficient mice showed higher frequency of DCs with immunogenic capacity [93]. We verified these findings in nonobese diabetic (NOD) mice, a well-established mouse model for Sjögren's-like syndrome. Administration of rGal-1 to NOD mice rescued the autoimmune phenotype showing a significant reduction of $\mathrm{CD} 45^{+}$cells within the salivary glands. Accordingly, labial biopsies from primary Sjögren's syndrome patients showed reduced Gal-1 expression concomitant with a higher number of infiltrating $\mathrm{CD}^{+} \mathrm{T}$ cells [93]. These findings demonstrate that endogenous Gal-1 plays a key role in preventing age-dependent development of spontaneous autoimmunity (Figure 3).

\section{Inflammatory bowel disease}

Inflammatory bowel diseases (IBD) constitute a group of multifactorial chronic disorders that affect the digestive tract, such as Crohn's disease (CD) and ulcerative colitis (UC). These disorders are characterized by a dysregulation of mucosal immune homeostasis, due to defects in tolerance induction against commensal microbiota or excessive activation of effector immune responses [119]. The 2,4,6-trinitrobenzenesulfonic acid (TNBS)-induced colitis mouse model recapitulates several features of IBD. In this model, the TNBS hapten is delivered into the mouse colonic lumen, eliciting an inflammatory immune response in the gut. The broad tolerogenic responses of Gal-1 prompted speculation on its potential regulatory role in the control of colitogenic immune responses in the inflamed gut. Administration of rGal-1 in this model resulted in an increased number of apoptotic T cells in the colonic lamina propria and a decreased frequency of Th1 cytokines in comparison with untreated mice [120]. Moreover, this lectin also maintained intestinal tissue homeostasis through the control of epithelial cell viability and regulation of epithelial-derived immunoregulatory cytokines [121] (Figure 3). Future studies should explore the exact role of this lectin and its glycosylated ligands on intestinal immune cell populations.

\section{Celiac disease}

Celiac disease is a T cell mediated disorder where chronic intestinal inflammation occurs as a result of immune responses to wheat gluten peptides. This dysregulated immune response has multifactorial etiology and up to now, the only effective treatment known is strict adherence to gluten-free diet [122]. We demonstrated an increased expression of Gal-1 in duodenal biopsies of celiac disease patients after a lifelong gluten-free diet, compared to patients who did not take this diet [88]. These findings suggested that this lectin might contribute to the resolution of chronic inflammation in response to gluten withdrawal. Moreover, Gal-1 could be considered as a potential biomarker for the follow-up of celiac disease patients [88]. Future studies should be aimed at analyzing the role of endogenous Gal-1 or exogenous rGal-1 administration in mouse models of celiac disease. 


\section{Uveitis}

Autoimmune uveitis is characterized by an inflammatory response that occurs in the uvea and can adversely affect vision leading to blindness [123]. Experimental autoimmune uveitis (EAU) is a mouse model of this intraocular inflammatory disease characterized by the inflammation and destruction of the neural retina. The disease is induced by immunization with retinal antigens such as interphotoreceptor retinoid binding protein (IRBP) and adjuvants like pertussis toxin (PTX). In this model, we demonstrated that the administration of rGal-1 decreased disease severity, mainly by reducing immune cell infiltration and shifting the Th1 response towards a Th2 or Treg cell profile [95]. Meanwhile, in the endotoxin-induced uveitis (EIU) model, the disease is induced by inoculation with lipopolysaccharide (LPS) in the rat's paw. Administration of rGal-1 to LPS-treated rats attenuated the histopathological manifestations of EIU, suppressing the expression of pro-inflammatory cytokines such as IL-6, IL-1 $\beta$, and monocyte chemotactic protein-1 (MCP-1), thus inhibiting polymorphonuclear cells infiltration [96]. Furthermore, in clinical settings, anti-Gal-1 autoantibodies correlated with the severity of ocular pathology in autoimmune and infectious uveitis [124]. Further studies should be aimed at analyzing the protective role of endogenous Gal-1 in preserving immune privilege in the eye and preventing ocular inflammation.

\section{Diabetes}

In type I diabetes, insulin-producing pancreatic $\beta$-cells are destroyed by autoreactive T cells [97]. Gal-1 demonstrated an anti-inflammatory role in spontaneous diabetes in NOD mice. This effect was accompanied by downregulation of T cell pro-inflammatory response and augmented frequency of $\mathrm{Th} 2$ responses, thus preventing hyperglycemia at early and subclinical stages [97]. Supporting these findings, patients with type 1 diabetes had lower serum levels of Gal-1 compared to healthy controls, mainly due to a reduced secretion of this lectin by monocytes [98] (Figure 3). Whether Gal-1-driven programs could link immune, endocrine, and metabolic pathways in diabetic individuals still remains to be elucidated.

\section{Orchitis}

Testicular inflammation and anti-sperm antibodies are the main features of autoimmune orchitis [125]. Given the high expression of Gal-1 in Sertoli testicular cells [126], we investigated the possible role of this lectin in autoimmune testicular inflammation. In a model of experimental autoimmune orchitis (EAO), we found that Gal-1 expression did not correlate with the extent of the inflammatory response. Paradoxically, in this model, Lgals $1^{-/}$mice showed a reduction in the incidence and severity of the disease. However, when rGal-1 was administered exogenously, inflammation was dampened, and clinical symptoms were attenuated similarly to other autoimmune inflammation models [99]. These results highlight the dual role of endogenous versus exogenous Gal-1 in this particular experimental model. Further studies should be aimed at dissecting innate and adaptive components differentially regulated by exogenous and endogenous Gal-1 in autoimmune testicular inflammation.

\section{Allergic Airway Inflammation}

Allergic airway inflammation is characterized by elevated recruitment of eosinophils to the lung and increased activation of antigen-specific Th2 responses. Murine models resembling allergic asthma involve acute or chronic exposure to ovalbumin (OVA). We evaluated the relevance of the Gal-1-glycan axis in this model. An immunohistochemical analysis revealed recruitment of Gal-1-expressing inflammatory eosinophils to the inflamed lungs [100]. Interestingly, Gal-1 expression was up-regulated in the epithelial cells, smooth muscle cells and endothelial cells of the lungs and within the extracellular space as a result of allergen exposure. Recombinant Gal-1 inhibited eosinophil migration through specific recognition of LacNAc residues on the surface of these cells. Moreover, in vivo studies showed augmented eosinophil and $\mathrm{T}$ cell recruitment to the airways in allergen-exposed Lgals $1^{-/}$compared to WT mice. Thus, allergen-challenged Lgals $1^{-/}$mice exhibited airway hyperresponsiveness that could be attributed to a lack of eosinophilia regulation by Gal-1 at inflammation sites [100]. Overall, this study showed an important role for Gal-1 in the resolution of airway inflammation through the control of eosinophils' migratory and functional capacity, opening therapeutic avenues for eosinophil-dependent inflammatory responses (Figure 3).

\section{Immune-related failing pregnancies}

The elevated amounts of Gal-1 during gestation in different species and its high sensitivity to hormonal regulation [127, 128], prompted us to investigate the role of this lectin during pregnancy. Consistent with a marked decrease in Gal-1 expression during failing pregnancies, $\operatorname{Lgals}^{-/-}$female mice showed higher rates of fetal loss compared to WT mice in 
allogeneic mating. Treatment with rGal-1 prevented fetal loss and restored tolerance through mechanisms involving expansion of IL-10-secreting Treg cells in vivo [129]. Supporting these findings, increased frequency of circulating antiGal-1 autoantibodies were detected in sera from women with spontaneous recurrent abortions compared to fertile women [130]. Interestingly, Gal-1 also controls sperm fertilizing activity [131], suggesting diverse roles for this lectin during mammalian reproduction and gestation.

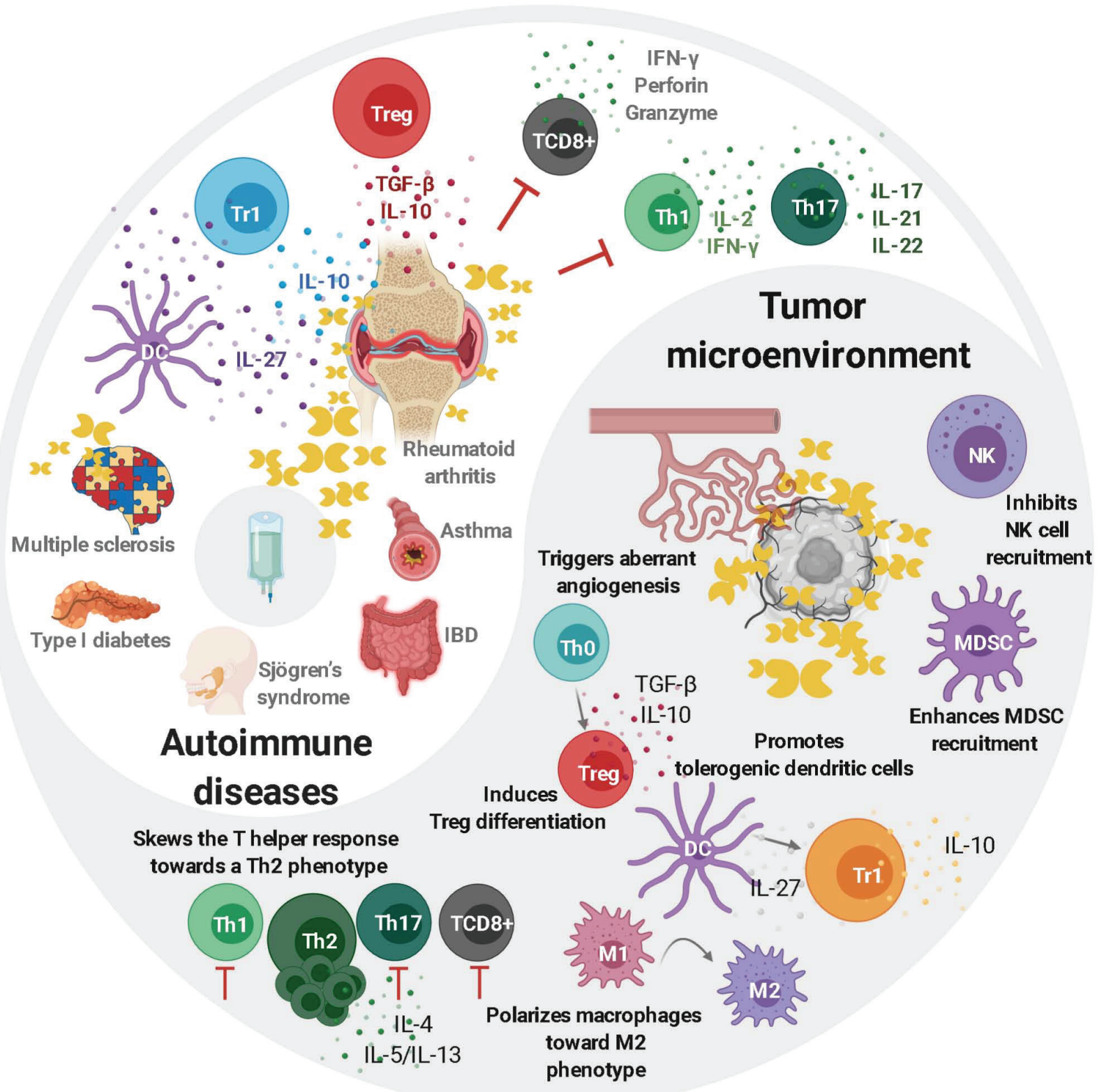

Figure 3. Contrasting roles of Gal-1 in autoimmunity and cancer. On the right, several immunosuppressive effects that Gal-1 exerts within the tumor microenvironment are illustrated, including induction of $\mathrm{CD} 8^{+} \mathrm{T}$ cell apoptosis, expansion of immunosuppressive Tregs, differentiation of tolerogenic DCs, induction of macrophage polarization from a proinflammatory M1 toward an anti-inflammatory M2 profile, and promotion of aberrant angiogenesis. Gal-1 blockade triggers an effective T cell-mediated anti-tumor response and control of tumor growth. On the left, the beneficial functions underlying the administration of rGal-1 in autoimmune diseases are outlined, including selective death of Th1 and Th17 lymphocytes, inhibition of pro-inflammatory cytokines, differentiation of tolerogenic DCs leading to expansion of Tr1 cells, and promotion of Treg cell expansion. Thus, administration of exogenous rGal-1 would favor the resolution of inflammatory and autoimmune processes. Created with BioRender.com. 


\section{Concluding remarks and future perspectives}

In this review, we discussed the multifunctional roles of Gal-1, an endogenous immunomodulatory $\beta$-galactoside binding protein, in cancer and autoimmune inflammation. Through recognition of terminal LacNAc residues present in complex branched $\mathrm{N}$-glycans and core-2 $\mathrm{O}$-glycan structures, this lectin recalibrates innate and adaptive responses by modulating the survival, activation, trafficking, and differentiation of immune cells. Expression of Gal-1 during peak and resolution phases of inflammatory responses contributes to restoring immune homeostasis by blunting exacerbated immune responses through induction of glycosylation-dependent tolerogenic circuits. Accordingly, dysregulation of Gal-1 expression and/or its glycosylated ligands contribute to the establishment and perpetuation of pathologic conditions.

On the one hand, interruption of Gal-1-glycan interactions leads to exacerbation of inflammatory and autoimmune responses. It has been demonstrated in a wide range of experimental models of autoimmune diseases that the absence of Gal-1 aggravates the clinical severity of the disease [49, 56, 92, 93, 112]. In this regard, we recently found that aged Lgals $1^{-/}$mice spontaneously develop a Sjögren's-like syndrome [93], providing clear-cut evidence of the central role of endogenous Gal-1 in the control of immune homeostatic programs. This effect was further validated by the broad immunomodulatory activity of exogenous rGal-1 in a broad range of autoimmune experimental models [90]. Interestingly, augmented T cell-dependent inflammatory responses have also been observed in mice lacking the Mgat5 glycosyltransferase, responsible for generating galectin ligands [17]. These findings place the Gal-1-glycan axis at the center of the scene of immune tolerance and homeostasis, highlighting a potential therapeutic target for T cell-dependent autoimmune inflammation. Since current therapies in autoimmune diseases are not curative and show substantial side effects [132], Gal-1-based immunomodulatory agonists emerge as potential immunomodulators to recalibrate immunity and restore immunological homeostasis.

On the other hand, in the context of neoplastic diseases, Gal-1 favors tumor growth and metastasis by fostering immunosuppression and angiogenesis. Since our initial discovery showing that melanoma cells evade $\mathrm{T}$ cell-mediated antitumor responses by secreting Gal-1 [48], this paradigm has been extended to a broad range of tumors including lung adenocarcinoma, Hodgkin lymphoma, pancreatic adenocarcinoma, glioblastoma, neuroblastoma, breast adenocarcinoma, CLL and others [58]. Additionally, this lectin stimulates the generation of aberrant vascular networks at sites of tumor growth and facilitates tumor-stroma interactions, favoring dissemination, colonization, and metastatic disease [65, 133]. Remarkably, this endogenous lectin confers resistance to different treatments including anti-angiogenic therapy, immunotherapy, chemotherapy, radiotherapy, and targeted therapies [134]. Collectively, these results underscore the potential therapeutic value of Gal-1 blockade, using neutralizing monoclonal antibodies, synthetic or natural glycans or antagonistic peptides [135], either alone or in combination with other therapeutic modalities for treating a wide range of tumors. Future basic and clinical research is awaited to validate galectin-based therapeutic strategies and translate these findings from bench to bedside and back again.

\section{Acknowledgements}

Work in our laboratory is supported by grants from Agencia Nacional de Promoción Científica y Tecnológica (2017-0494), Fundación Sales, Fundación Bunge \& Born and Richard Lounsbery Foundation to G.A.R. We thank all members of the Immunopathology, Functional Glycomics and Translational Immuno Oncology laboratories of IBYME for continuous support. C.A.B., A.M.C., Y.D.M., M.N.M.C., M.M, J.P.M., R.M.P., N.S., L.L. and F.V. thank CONICET for their PhD fellowships.

\section{References}

[1] Ohtsubo, K. \& Marth, J. D. Glycosylation in Cellular Mechanisms of Health and Disease. Cell 126, 855-867 (2006).

[2] Bard, F. \& Chia, J. Cracking the Glycome Encoder: Signaling, Trafficking, and Glycosylation. Trends Cell Biol. 26, 379-388 (2016).

[3] Moremen, K. W., Tiemeyer, M. \& Nairn, A. V. Vertebrate protein glycosylation: Diversity, synthesis and function. Nat. Rev. Mol. Cell Biol. 13, 448-462 (2012).

[4] Cerliani, J. P., Blidner, A. G., Toscano, M. A., Croci, D. O. \& Rabinovich, G. A. Translating the "Sugar Code" into Immune and Vascular Signaling Programs'. Trends Biochem. Sci. 42, 255-273 (2017).

[5] Marth, J. D. \& Grewal, P. K. Mammalian glycosylation in immunity. Nat. Rev. Immunol. 8, 874-887 (2008). 
[6] Duan, S. \& Paulson, J. C. Siglecs as Immune Cell Checkpoints in Disease. Annu. Rev. Immunol. 38, 365-395 (2020).

[7] Chugh, S., Gnanapragassam, V. S., Jain, M., Rachagani, S., Ponnusamy, M. P. \& Batra, S. K. Pathobiological implications of mucin glycans in cancer: Sweet poison and novel targets. Biochim. Biophys. Acta 1856, 211-225 (2015).

[8] Albrecht, S., Unwin, L., Muniyappa, M. \& Rudd, P. M. Glycosylation as a marker for inflammatory arthritis. Cancer Biomarkers 14, 17-28 (2014).

[9] Johnson, J. L., Jones, M. B., Ryan, S. O. \& Cobb, B. A. The regulatory power of glycans and their binding partners in immunity. Trends Immunol. 34, 290-298 (2013).

${ }^{[10]}$ Rabinovich, G. A. \& Toscano, M. A. Turning 'sweet' on immunity: galectin-glycan interactions in immune tolerance and inflammation. Nat Rev Immunol 9, 338-352 (2009).

${ }^{[11]}$ Rodrigues, J. G., Balmaña, M., Macedo, J. A., Poças, J., Fernandes, Â., de-Freitas-Junior, J. C. M., Pinho, S. S., Gomes, J., Magalhães, A., Gomes, C., Mereiter, S. \& Reis, C. A. Glycosylation in cancer: Selected roles in tumour progression, immune modulation and metastasis. Cell. Immunol. 333, 46-57 (2018).

${ }^{[12]}$ Rabinovich, G. A. \& Croci, D. O. Regulatory Circuits Mediated by Lectin-Glycan Interactions in Autoimmunity and Cancer. Immunity 36, 322-335 (2012).

${ }^{[13]}$ Park, C., Jin, U. H., Lee, Y. C., Cho, T. J. \& Kim, C. H. Characterization of UDP-N-acetylglucosamine: $\alpha-6-D-$ mannoside $\beta-1,6-\mathrm{N}$ - acetylglucosaminyltransferase V from a human hepatoma cell line Hep3B. Arch. Biochem. Biophys. 367, 281-288 (1999).

${ }^{[14]}$ Nagae, M., Kizuka, Y., Mihara, E., Kitago, Y., Hanashima, S., Ito, Y., Takagi, J., Taniguchi, N. \& Yamaguchi, Y. Structure and mechanism of cancer-associated N-acetylglucosaminyltransferase-V. Nat. Commun. 9, (2018).

[15] van Kooyk, Y. \& Rabinovich, G. A. Protein-glycan interactions in the control of innate and adaptive immune responses. Nat. Immunol. 9, 593-601 (2008).

[16] Dam, T. K. \& Brewer, F. C. Maintenance of cell surface glycan density by lectin-glycan interactions: A homeostatic and innate immune regulatory mechanism. Glycobiology 20, 1061-1064 (2010).

[17] Dennis, J. W., Nabi, I. R. \& Demetriou, M. Metabolism, Cell Surface Organization, and Disease. Cell 139, 1229-1241 (2009).

${ }^{[18]}$ Nabi, I. R., Shankar, J. \& Dennis, J. W. The galectin lattice at a glance. J. Cell Sci. 128, 2213-2219 (2015).

[19] Drickamer, K. Engineering galactose-binding activity into a C-type mannose-binding protein. Nature 360, 183-186 (1992).

${ }^{[20]}$ Brown, G. D. \& Gordon, S. A new receptor for $\beta$-glucans. Nature 413, 36-37 (2001).

[21] Osorio, F. \& Reis e Sousa, C. Myeloid C-type Lectin Receptors in Pathogen Recognition and Host Defense. Immunity 34, 651-664 (2011).

${ }^{[22]}$ Crocker, P. R., Paulson, J. C. \& Varki, A. Siglecs and their roles in the immune system. Nat. Rev. Immunol. 7, 255-266 (2007).

${ }^{[23]}$ Liu, F.-T., Patterson, R. J. \& Wang, J. L. Intracellular functions of galectins. Biochim. Biophys. Acta 1572, 263-273 (2002).

${ }^{[24]}$ Rabinovich, G. A., Toscano, M. A., Jackson, S. S. \& Vasta, G. R. Functions of cell surface galectin-glycoprotein lattices. Curr. Opin. Struct. Biol. 17, 513-520 (2007).

[25] Yang, R. Y., Rabinovich, G. A. \& Liu, F. T. Galectins: Structure, function and therapeutic potential. Expert Rev. Mol. Med. 10, 1-24 (2008).

[26] Brinchmann, M. F., Patel, D. M. \& Iversen, M. H. The role of galectins as modulators of metabolism and inflammation. Mediators Inflamm. 2018, (2018). 
[27] Vasta, G. R., Feng, C., González-Montalbán, N., Mancini, J., Yang, L., Abernathy, K., Frost, G. \& Palm, C. Functions of galectins as 'self/non-self'-recognition and effector factors. Pathog. Dis. 75, 1-12 (2017).

${ }^{[28]}$ Rabinovich, G. A., Toscano, M. A., Jackson, S. S. \& Vasta, G. R. Functions of cell surface galectin-glycoprotein lattices. Curr. Opin. Struct. Biol. 17, 513-520 (2007).

${ }^{[29]}$ Hirabayashi, J., Hashidate, T., Arata, Y., Nishi, N., Nakamura, T., Hirashima, M., Urashima, T., Oka, T., Futai, M., Muller, W. E. G., Yagi, F. \& Kasai, K. I. Oligosaccharide specificity of galectins: A search by frontal affinity chromatography. Biochim. Biophys. Acta - Gen. Subj. 1572, 232-254 (2002).

[30] Thiemann, S. \& Baum, L. G. Galectins and Immune Responses-Just How Do They Do Those Things They Do? Annu. Rev. Immunol. 34, 243-264 (2016).

[31] Kamili, N. A., Arthur, C. M., Gerner-Smidt, C., Tafesse, E., Blenda, A., Dias-Baruffi, M. \& Stowell, S. R. Key regulators of galectin-glycan interactions. Proteomics 16, 3111-3125 (2016).

${ }^{[32]}$ Maller, S. M., Cagnoni, A. J., Bannoud, N., Sigaut, L., Pérez Sáez, J. M., Pietrasanta, L. I., Yang, R. Y., Liu, F. T., Croci, D. O., Di Lella, S., Sundblad, V., Rabinovich, G. A. \& Mariño, K. V. An adipose tissue galectin controls endothelial cell function via preferential recognition of 3-fucosylated glycans. FASEB J. 34, 735-753 (2019).

[33] Patnaik, S. K., Potvin, B., Carlsson, S., Sturm, D., Leffler, H. \& Stanley, P. Complex N-glycans are the major ligands for galectin-1, -3, and -8 on Chinese hamster ovary cells. Glycobiology 16, 305-317 (2006).

[34] Stowell, S. R., Arthur, C. M., Mehta, P., Slanina, K. A., Blixt, O., Leffler, H., Smith, D. F. \& Cummings, R. D. Galectin-1, -2, and -3 exhibit differential recognition of sialylated glycans and blood group antigens. J. Biol. Chem. 283, 10109-10123 (2008).

[35] Ideo, H., Matsuzaka, T., Nonaka, T., Seko, A. \& Yamashita, K. Galectin-8-N-Domain Recognition Mechanism for Sialylated and Sulfated Glycans. J. Biol. Chem. 286, 11346-11355 (2011).

[36] Rabinovich, G. A. \& Gruppi, A. Galectins as immunoregulators during infectious processes: From microbial invasion to the resolution of the disease. Parasite Immunol. 27, 103-114 (2005).

[37] Vasta, G. R. Roles of galectins in infection. Nat. Rev. Microbiol. 7, 424-438 (2009).

[38] Waldman, A. D., Fritz, J. M. \& Lenardo, M. J. A guide to cancer immunotherapy: from T cell basic science to clinical practice. Nat. Rev. Immunol. 1-18 (2020) doi:10.1038/s41577-020-0306-5.

${ }^{[39]}$ Decker, W. K. \& Safdar, A. Bioimmunoadjuvants for the treatment of neoplastic and infectious disease: Coley's legacy revisited. Cytokine Growth Factor Rev. 20, 271-281 (2009).

${ }^{[40]}$ Decker, W. K., da Silva, R. F., Sanabria, M. H., Angelo, L. S., Guimarães, F., Burt, B. M., Kheradmand, F. \& Paust, S. Cancer immunotherapy: Historical perspective of a clinical revolution and emerging preclinical animal models. Front. Immunol. 8, (2017).

[41] Topalian, S. L., Hodi, F. S., Brahmer, J. R., Gettinger, S. N., Smith, D. C., McDermott, D. F., Powderly, J. D., Carvajal, R. D., Sosman, J. A., Atkins, M. B., Leming, P. D., Spigel, D. R., Antonia, S. J., Horn, L., Drake, C. G., Pardoll, D. M., Chen, L., Sharfman, W. H., Anders, R. A., Taube J. M., McMiller T. L., Xu H., Korman A. J., Jure-Kunkel M., Agrawal S., McDonald D., Kollia G. D. , Gupta A., Wigginton J. M. \& Sznol, M. Safety, activity, and immune correlates of anti-PD-1 antibody in cancer. N. Engl. J. Med. 366, 2443-2454 (2012).

${ }^{[42]}$ Postow, M. A., Chesney, J., Pavlick, A. C., Robert, C., Grossmann, K., McDermott, D., Linette, G. P., Meyer, N., Giguere, J. K., Agarwala, S. S., Shaheen, M., Ernstoff, M. S., Minor, D., Salama, A. K., Taylor, M., Ott, P. A., Rollin, L. M., Horak, C., Gagnier, P., Wolchok, J. D. \& Hodi, F. S. Nivolumab and ipilimumab versus ipilimumab in untreated melanoma. N. Engl. J. Med. 372, 2006-2017 (2015).

[43] Schmid, P., Cortes, J., Pusztai, L., McArthur, H., Kümmel, S., Bergh, J., Denkert, C., Park, Y. H., Hui, R., Harbeck, N., Takahashi, M., Foukakis, T., Fasching, P. A., Cardoso, F., Untch, M., Jia, L., Karantza, V., Zhao, J., Aktan, G., Dent, R. \& O'Shaughnessy, J. for the KEYNOTE-522 Investigators. Pembrolizumab for early triple-negative breast cancer. N. Engl. J. Med. 382, 810-821 (2020).

${ }^{[44]}$ Gandhi, L., Rodríguez-Abreu, D., Gadgeel, S., Esteban, E., Felip, E., De Angelis, F., Domine, M., Clingan, P., 
Hochmair, M. J., Powell, S. F., Cheng, S. Y., Bischoff, H. G., Peled, N., Grossi, F., Jennens, R. R., Reck, M., Hui, R., Garon, E. B., Boyer, M., Rubio-Viqueira, B., Novello, S., Kurata, T., Gray, J. E., Vida, J., Wei, Z., Yang, J., Raftopoulos, H., Pietanza, M. C. \& Garassino, M. C. for the KEYNOTE-189 Investigators. Pembrolizumab plus chemotherapy in metastatic non-small-cell lung cancer. N. Engl. J. Med. 378, 2078-2092 (2018).

${ }^{[45]}$ Fares, C. M., Van Allen, E. M., Drake, C. G., Allison, J. P. \& Hu-Lieskovan, S. Mechanisms of Resistance to Immune Checkpoint Blockade: Why Does Checkpoint Inhibitor Immunotherapy Not Work for All Patients? Am. Soc. Clin. Oncol. Educ. B. 147-164 (2019) doi:10.1200/edbk_240837.

[46] Jenkins, R. W., Barbie, D. A. \& Flaherty, K. T. Mechanisms of resistance to immune checkpoint inhibitors. Br. $J$. Cancer 118, 9-16 (2018).

${ }^{[47]}$ Anderson, A. C., Joller, N. \& Kuchroo, V. K. Lag-3, Tim-3, and TIGIT: Co-inhibitory Receptors with Specialized Functions in Immune Regulation. Immunity 44, 989-1004 (2016).

${ }^{[48]}$ Rubinstein, N., Alvarez, M., Zwirner, N. W., Toscano, M. A., Ilarregui, J. M., Bravo, A., Mordoh, J., Fainboim, L., Podhajcer, O. L. \& Rabinovich, G. A. Targeted inhibition of galectin-1 gene expression in tumor cells results in heightened T cell-mediated rejection; A potential mechanism of tumor-immune privilege. Cancer Cell 5, 241-251 (2004).

[49] Toscano, M. A., Bianco, G. A., Ilarregui, J. M., Croci, D. O., Correale, J., Hernandez, J. D., Zwirner, N. W., Poirier, F., Riley, E. M., Baum, L. G. \& Rabinovich, G. A. Differential glycosylation of TH1, TH2 and TH-17 effector cells selectively regulates susceptibility to cell death. Nat. Immunol. 8, 825-834 (2007).

[50] Juszczynski, P., Ouyang, J., Monti, S., Rodig, S. J., Takeyama, K., Abramson, J., Chen, W., Kutok, J. L., Rabinovich, G. A. \& Shipp, M. A. The AP1-dependent secretion of galectin-1 by Reed-Sternberg cells fosters immune privilege in classical Hodgkin lymphoma. Proc. Natl. Acad. Sci. U. S. A. 104, 13134-13139 (2007).

[51] Kamper, P., Ludvigsen, M., Bendix, K., Hamilton-Dutoit, S., Rabinovich, G. A., Møller, M. B., Nyengaard, J. R., Honoré, B. \& d'Amore, F. Proteomic analysis identifies galectin-1 as a predictive biomarker for relapsed/refractory disease in classical Hodgkin lymphoma. Blood 117, 6638-6649 (2011).

${ }^{[52]}$ Dalotto-Moreno, T., Croci, D. O., Cerliani, J. P., Martinez-Allo, V. C., Dergan-Dylon, S., Méndez-Huergo, S. P., Stupirski, J. C., Mazal, D., Osinaga, E., Toscano, M. A., Sundblad, V., Rabinovich, G. A. \& Salatino, M. Targeting galectin-1 overcomes breast cancer-associated immunosuppression and prevents metastatic disease. Cancer Res. 73, 1107-1117 (2013).

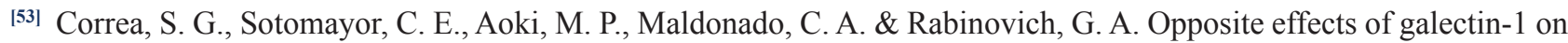
alternative metabolic pathways of L-arginine in resident, inflammatory, and activated macrophages. Glycobiology 13, 119-128 (2003).

${ }^{[54]}$ Barrionuevo, P., Beigier-Bompadre, M., Ilarregui, J. M., Toscano, M. A., Bianco, G. A., Isturiz, M. A. \& Rabinovich, G. A. A Novel Function for Galectin-1 at the Crossroad of Innate and Adaptive Immunity: Galectin-1 Regulates Monocyte/Macrophage Physiology through a Nonapoptotic ERK-Dependent Pathway. J. Immunol. 178, 436-445 (2007).

[55] Verschuere, T., Toelen, J., Maes, W., Poirier, F., Boon, L., Tousseyn, T., Mathivet, T., Gerhardt, H., Mathieu, V., Kiss, R., Lefranc, F., Van Gool, S. W. \& De Vleeschouwer, S. Glioma-derived galectin-1 regulates innate and adaptive antitumor immunity. Int. J. Cancer 134, 873-884 (2014).

[56] Ilarregui, J. M., Croci, D. O., Bianco, G. A., Toscano, M.A., Salatino, M., Vermeulen, M. E., Geffner, J. R. \& Rabinovich, G. A. Tolerogenic signals delivered by dendritic cells to T cells through a galectin-1-driven immunoregulatory circuit involving interleukin 27 and interleukin 10. Nat. Immunol. 10, 981-991 (2009).

[57] Soldati, R., Berger, E., Zenclussen, A. C., Jorch, G., Lode, H. N., Salatino, M., Rabinovich, G. A. \& Fest, S. Neuroblastoma triggers an immunoevasive program involving galectin-1-dependent modulation of T cell and dendritic cell compartments. Int. J. Cancer 131, 1131-1141 (2012).

${ }^{[58]}$ Rabinovich, G. A. \& Conejo-García, J. R. Shaping the Immune Landscape in Cancer by Galectin-Driven Regulatory Pathways. J. Mol. Biol. 428, 3266-3281 (2016).

${ }^{[59]}$ Laderach, D. J., Gentilini, L. D., Giribaldi, L., Delgado, V. C., Nugnes, L., Croci, D. O., Al Nakouzi, N., Sacca, P., 
Casas, G., Mazza, O., Shipp, M. A., Vazquez, E., Chauchereau, A., Kutok, J. L., Rodig, S. J., Elola, M. T., Compagno, D. \& Rabinovich, G. A. A unique galectin signature in human prostate cancer progression suggests galectin-1 as a key target for treatment of advanced disease. Cancer Res. 73, 86-96 (2013).

${ }^{[60]}$ Orozco, C. A., Martinez-Bosch, N., Guerrero, P. E., Vinaixa, J., Dalotto-Moreno, T., Iglesias, M., Moreno, M., Djurec, M., Poirier, F., Gabius, H. J., Fernandez-Zapico, M. E., Hwang, R. F., Guerra, C., Rabinovich, G. A. \& Navarro, P. Targeting galectin-1 inhibits pancreatic cancer progression by modulating tumor-stroma crosstalk. Proc. Natl. Acad. Sci. U. S. A. 115, E3769--E3778 (2018).

${ }^{[61]}$ Holst, J. M., Ludvigsen, M., Hamilton-Dutoit, S. J., Bendix, K., Plesner, T. L., Nørgaard, P., Møller, M. B., Steiniche, T., Rabinovich, G. A., D’Amore, F. \& Pedersen, M. B. High intratumoural galectin-1 expression predicts adverse outcome in ALK- ALCL and CD30+ PTCL-NOS. Hematol. Oncol. 38, 59-66 (2020).

${ }^{[62]}$ Nambiar, D. K., Aguilera, T., Cao, H., Kwok, S., Kong, C., Bloomstein, J., Wang, Z., Rangan, V. S., Jiang, D., von Eyben, R., Liang, R., Agarwal, S., Colevas, A. D., Korman, A., Allen, C. T., Uppaluri, R., Koong, A. C., Giaccia, A., \& Le, Q. T.. Galectin-1-driven T cell exclusion in the tumor endothelium promotes immunotherapy resistance. J. Clin. Invest. 129, 5553-5567 (2019).

${ }^{[63]}$ Rutkowski, M. R., Stephen, T. L., Svoronos, N., Allegrezza, M. J., Tesone, A. J., Perales-Puchalt, A., Brencicova, E., Escovar-Fadul, X., Nguyen, J. M., Cadungog, M. G., Zhang, R., Salatino, M., Tchou, J., Rabinovich, G. A. \& Conejo-Garcia, J. R. Microbially driven TLR5-dependent signaling governs distal malignant progression through tumor-promoting inflammation. Cancer Cell 27, 27-40 (2015).

${ }^{[64]}$ Croci, D. O., Salatino, M., Rubinstein, N., Cerliani, J. P., Cavallin, L. E., Leung, H. J., Ouyang, J., Ilarregui, J. M., Toscano, M. A., Domaica, C. I., Croci, M. C., Shipp, M. A., Mesri, E. A., Albini, A. \& Rabinovich, G. A. Disrupting galectin-1 interactions with N-glycans suppresses hypoxia-driven angiogenesis and tumorigenesis in Kaposi's sarcoma. J. Exp. Med. 209, 1985-2000 (2012).

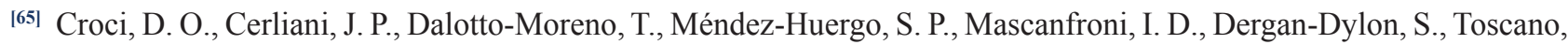
M. A., Caramelo, J. J., García-Vallejo, J. J., Ouyang, J., Mesri, E. A., Junttila, M. R., Bais, C., Shipp, M. A., Salatino, M. \& Rabinovich, G. A. Glycosylation-dependent lectin-receptor interactions preserve angiogenesis in anti-VEGF refractory tumors. Cell 156, 744-758 (2014).

${ }^{[66]} \mathrm{Wu}$, X., Li, J., Connolly, E. M., Liao, X., Ouyang, J., Giobbie-Hurder, A., Lawrence, D., Mcdermott, D., Murphy, G., Zhou, J., Piesche, M., Dranoff, G., Rodig, S., Shipp, M. \& Hodi, F. S. Combined Anti-VEGF and Anti-CTLA-4 therapy elicits humoral immunity to galectin-1 which is associated with favorable clinical outcomes. Cancer Immunol. Res. 5, 446-454 (2017).

${ }^{[67]}$ Fidler, I. J. The pathogenesis of cancer metastasis: the 'seed and soil' hypothesis revisited. Nat. Rev. Cancer 3, 453458 (2003).

[68] Giancotti, F. G. XMechanisms governing metastatic dormancy and reactivation. Cell 155, 750 (2013).

${ }^{[69]}$ Liu, F.-T. \& Rabinovich, G. A. Galectins as modulators of tumour progression. Nat. Rev. Cancer 5, 29-41 (2005).

${ }^{[70]}$ Ellerhorst, J. Differential expression of endogenous galectin-1 and gaIectin-3 in human prostate cancer cell lines and effects of overexpressing galectin-1 on cell phenotype. Int. J. Oncol. 14, 217-224 (1999).

[11] Moiseeva, E. P., Spring, E. L., Baron, J. H. \& De Bono, D. P. Galectin 1 modulates attachment, spreading and migration of cultured vascular smooth muscle cells via interactions with cellular receptors and components of extracellular matrix. J. Vasc. Res. 36, 47-58 (1999).

[72] Van den Brûle, F., Califice, S., Garnier, F., Fernandez, P. L., Berchuck, A. \& Castronovo, V. Galectin-1 accumulation in the ovary carcinoma peritumoral stroma is induced by ovary carcinoma cells and affects both cancer cell proliferation and adhesion to laminin-1 and fibronectin. Lab. Investig. 83, 377-386 (2003).

${ }^{[73]}$ Lotan, R., Belloni, P. N., Tressler, R. J., Lotan, D., Xu, X. C. \& Nicolson, G. L. Expression of galectins on microvessel endothelial cells and their involvement in tumour cell adhesion. Glycoconj. J. 11, 462-468 (1994).

[74] Tinari, N., Kuwabara, I., Huflejt, M. E., Shen, P. F., Iacobelli, S. \& Liu, F. T. Glycoprotein 90K/mac-2bp interacts with galectin-1 and mediates galectin-1-induced cell aggregation. Int. J. Cancer 91, 167-172 (2001). 
${ }^{[75]}$ Chiang, W. F., Liu, S. Y., Fang, L. Y., Lin, C. N., Wu, M. H., Chen, Y. C., Chen, Y. L. \& Jin, Y. T. Overexpression of galectin-1 at the tumor invasion front is associated with poor prognosis in early-stage oral squamous cell carcinoma. Oral Oncol. 44, 325-334 (2008).

[76] Wu, M. H., Hong, T. M., Cheng, H. W., Pan, S. H., Liang, Y. R., Hong, H. C., Chiang, W. F., Wong, T. Y., Shieh, D. Bin, Shiau, A. L., Jin, Y. T. \& Chen, Y. L. Galectin-1-Mediated tumor invasion and metastasis, Up-Regulated matrix metalloproteinase expression, and reorganized actin cytoskeletons. Mol. Cancer Res. 7, 311-318 (2009).

[77] Jung, E. J., Moon, H. G., Bok, I. C., Jeong, C. Y., Joo, Y. T., Lee, Y. J., Hong, S. C., Choi, S. K., Ha, W. S., Jae, W. K., Lee, C. W., Jong, S. L. \& Park, S. T. Galectin-1 expression in cancer-associated stromal cells correlates tumor invasiveness and tumor progression in breast cancer. Int. J. Cancer 120, 2331-2338 (2007).

${ }^{[78]}$ Bacigalupo, M. L., Manzi, M., Espelt, M. V, Gentilini, L. D., Compagno, D., Laderach, D. J., Wolfenstein-Todel, C., Rabinovich, G. A. \& Troncoso, M. F. Galectin-1 Triggers Epithelial-Mesenchymal Transition in Human Hepatocellular Carcinoma Cells. J. Cell. Physiol. 230, 1298-1309 (2015).

${ }^{[79]}$ He, X. J., Tao, H. Q., Hu, Z. M., Ma, Y. Y., Xu, J., Wang, H. J., Xia, Y. J., Li, L., Fei, B. Y., Li, Y. Q. \& Chen, J. Z. Expression of galectin-1 in carcinoma-associated fibroblasts promotes gastric cancer cell invasion through upregulation of integrin $\beta 1$. Cancer Sci. 105, 1402-1410 (2014).

${ }^{[80]}$ Chong, Y., Tang, D., Gao, J., Jiang, X., Xu, C., Xiong, Q., Huang, Y., Wang, J., Zhou, H., Shi, Y. \& Wang, D. Galectin-1 induces invasion and the epithelial-mesenchymal transition in human gastric cancer cells via non-canonical activation of the hedgehog signaling pathway. Oncotarget 7, 83611-83626 (2016).

[81] Tang, D., Zhang, J., Yuan, Z., Zhang, H., Chong, Y., Huang, Y., Wang, J., Xiong, Q., Wang, S., Wu, Q., Tian, Y., Lu, Y., Ge, X., Shen, W. \& Wang, D. PSC-derived Galectin-1 inducing epithelial-mesenchymal transition of pancreatic ductal adenocarcinoma cells by activating the NF-kB pathway. Oncotarget 8, 86488-86502 (2017).

${ }^{[82]}$ Shih, T. C., Liu, R., Wu, C. Te, Li, X., Xiao, W., Deng, X., Kiss, S., Wang, T., Chen, X. J., Carney, R., Kung, H. J., Duan, Y., Ghosh, P. M. \& Lam, K. S. Targeting galectin-1 impairs castration-resistant prostate cancer progression and invasion. Clin. Cancer Res. 24, 4319-4331 (2018).

${ }^{[83]}$ Cimmino, F., Schulte, J. H., Zollo, M., Koster, J., Versteeg, R., Iolascon, A., Eggert, A. \& Schramm, A. Galectin-1 is a major effector of TrkB-mediated neuroblastoma aggressiveness. Oncogene 28, 2015-2023 (2009).

[84] Sanchez-Vega, F., Mina, M., Armenia, J., Chatila, W. K., Luna, A., La, K. C., Dimitriadoy, S., Liu, D. L., Kantheti, H. S., Saghafinia, S., Chakravarty, D., Daian, F., Gao, Q., Bailey, M. H., Liang, W. W., Foltz, S. M., Shmulevich, I., Ding, L., Heins, Z., Ochoa, A., Gross, B., Gao, J., Zhang, H., Kundra, R., Kandoth, C., Bahceci, I., Dervishi, L., Dogrusoz, U., Zhou, W., Shen, H., Laird, P. W., Way, G. P., Greene, C. S., Liang, H., Xiao, Y., Wang, C., Lavarone, A., Berger, A. H., Bivona, T. G., Lazar, A. J., Hammer, G. D., Giordano, T., Kwong, L. N., McArthur, G., Huang, C., Tward, A. D., Frederick, M. J., McCormick, F., Meyerson, M., Cancer Genome Atlas Research Network, Van Allen, E. M., Cherniack, A. D., Ciriello, G., Sander, C. \& Schultz, N. Oncogenic Signaling Pathways in The Cancer Genome Atlas. Cell 173, 321--337.e10 (2018).

[85] Paz, A., Haklai, R., Elad-Sfadia, G., Ballan, E. \& Kloog, Y. Galectin-1 binds oncogenic H-Ras to mediate Ras membrane anchorage and cell transformation. Oncogene 20, 7486-7493 (2001).

${ }^{[86]}$ Elad-Sfadia, G., Haklai, R., Balan, E. \& Kloog, Y. Galectin-3 augments K-ras activation and triggers a ras signal that attenuates ERK but not phosphoinositide 3-kinase activity. J. Biol. Chem. 279, 34922-34930 (2004).

${ }^{[87]}$ Chung, L. Y., Tang, S. J., Sun, G. H., Chou, T. Y., Yeh, T. S., Yu, S. L. \& Sun, K. H. Galectin-1 promotes lung cancer progression and chemoresistance by upregulating p38 MAPK, ERK, and cyclooxygenase-2. Clin. Cancer Res. 18, 4037-4047 (2012).

[88] Sundblad, V., Quintar, A. A., Morosi, L. G., Niveloni, S. I., Cabanne, A., Smecuol, E., Mauriño, E., Mariño, K. V, Bai, J. C., Maldonado, C. A. \& Rabinovich, G. A. Galectins in Intestinal Inflammation: Galectin-1 Expression Delineates Response to Treatment in Celiac Disease Patients. Front. Immunol. 9, 379 (2018).

${ }^{[89]}$ Mendez-Huergo, S. P., Hockl, P. F., Stupirski, J. C., Maller, S. M., Morosi, L. G., Pinto, N. A., Berón, A. M., Musuruana, J. L., Nasswetter, G. G., Cavallasca, J. A. \& Rabinovich, G. A. Clinical Relevance of Galectin-1 and Galectin-3 in Rheumatoid Arthritis Patients: Differential Regulation and Correlation With Disease Activity. Front. Immunol. 9, (2019). 
[90] Toscano, M. A., Martínez Allo, V. C., Cutine, A. M., Rabinovich, G. A. \& Mariño, K. V. Untangling Galectin-Driven Regulatory Circuits in Autoimmune Inflammation. Trends Mol. Med. 24, 348-363 (2018).

[91] Rabinovich, G. A., Daly, G., Dreja, H., Tailor, H., Riera, C. M., Hirabayashi, J. \& Chernajovsky, Y. Recombinant Galectin-1 and Its Genetic Delivery Suppress Collagen-Induced Arthritis via T Cell Apoptosis. J. Exp. Med. 190, 385-398 (1999).

${ }^{[92]}$ Iqbal, A. J., Cooper, D., Vugler, A., Gittens, B. R., Moore, A. \& Perretti, M. Endogenous Galectin-1 Exerts Tonic Inhibition on Experimental Arthritis. J. Immunol. 191, 171-177 (2013).

[93] Martínez Allo, V. C., Hauk, V., Sarbia, N., Pinto, N. A., Croci, D. O., Dalotto-Moreno, T., Morales, R. M., Gatto, S. G., Manselle Cocco, M. N., Stupirski, J. C., Deladoey, Á., Maronna, E., Marcaida, P., Durigan, V., Secco, A., Mamani, M., Dos Santos, A., Catalán Pellet, A., Pérez Leiros, C., Rabinovich, G. A. \& Toscano, M. A. Suppression of age-related salivary gland autoimmunity by glycosylation-dependent galectin-1driven immune inhibitory circuits. Proc. Natl. Acad. Sci. U. S. A. 117, (2020).

[94] Santucci, L., Fiorucci, S., Rubinstein, N., Mencarelli, A., Palazzetti, B., Federici, B., Rabinovich, G.A. and Morelli, A. Galectin-1 suppresses experimental colitis in mice. Gastroenterology 124:1381-1394 (2003).

[95] Toscano, M. A., Commodaro, A. G., Ilarregui, J. M., Bianco, G. A., Liberman, A., Serra, H. M., Hirabayashi, J., Rizzo, L. V \& Rabinovich, G. A. Galectin-1 suppresses autoimmune retinal disease by promoting concomitant Th2- and T regulatory-mediated anti-inflammatory responses. J. Immunol. 176, 6323-6332 (2006).

[96] Zanon, C. de F., Sonehara, N. M., Girol, A. P., Gil, C. D. \& Oliani, S. M. Protective effects of the galectin-1 protein on in vivo and in vitro models of ocular inflammation. Mol. Vis. 21, 1036-1050 (2015).

${ }^{[97]}$ Perone, M. J., Bertera, S., Shufesky, W. J., Divito, S. J., Montecalvo, A., Mathers, A. R., Larregina, A. T., Pang, M., Seth, N., Wucherpfennig, K. W., Trucco, M., Baum, L. G. \& Morelli, A. E. Suppression of Autoimmune Diabetes by Soluble Galectin-1. J. Immunol. 182, 2641-2653 (2009).

[98] Gómez-Touriño, I., Sánchez-Espinel, C., Hernández-Fernández, A., González-Fernández, Á., Pena-González, E., Rodríguez, J., García-López, J. M. \& Varela-Calvino, R. Galectin-1 synthesis in type 1 diabetes by different immune cell types: Reduced synthesis by monocytes and Th1 cells. Cell. Immunol. 271, 319-328 (2011).

${ }^{[99]}$ Pérez, C. V, Gómez, L. G., Gualdoni, G. S., Lustig, L., Rabinovich, G. A. \& Guazzone, V. A. Dual roles of endogenous and exogenous galectin-1 in the control of testicular immunopathology. Sci. Rep. 5, 12259 (2015).

${ }^{[100]}$ Ge, X. N., Ha, S. G., Greenberg, Y. G., Rao, A., Bastan, I., Blidner, A. G., Rao, S. P., Rabinovich, G. A. \& Sriramarao, P. Regulation of eosinophilia and allergic airway inflammation by the glycan-binding protein galectin-1. Proc. Natl. Acad. Sci. 113, E4837--E4846 (2016).

${ }^{[101]}$ Stys, P. K., Zamponi, G. W., van Minnen, J. \& Geurts, J. J. G. Will the real multiple sclerosis please stand up? Nat. Rev. Neurosci. 13, 507-514 (2012).

${ }^{[102]}$ Stancic, M., van Horssen, J., Thijssen, V. L., Gabius, H.-J., van der Valk, P., Hoekstra, D. \& Baron, W. Increased expression of distinct galectins in multiple sclerosis lesions. Neuropathol. Appl. Neurobiol. 37, 654-671 (2011).

${ }^{[103]}$ Mendez-Huergo, S. P., Maller, S. M., Farez, M. F., Mariño, K., Correale, J. \& Rabinovich, G. A. Integration of lectin-glycan recognition systems and immune cell networks in CNS inflammation. Cytokine Growth Factor Rev. 25, 247-255 (2014).

${ }^{[104]}$ Steinman, L. Assessment of animal models for MS and demyelinating disease in the design of rational therapy. Neuron 24, 511-514 (1999).

${ }^{[105]}$ Furlan, R., Cuomo, C. \& Martino, G. Animal Models of Multiple Sclerosis. in Neural Cell Transplantation: Methods and Protocols (eds. Gordon, D. \& Scolding, N. J.) 157-173 (Humana Press, 2009). doi:10.1007/978-1-60327-9314_11.

${ }^{[106]}$ Passos, G. R. Dos, Sato, D. K., Becker, J. \& Fujihara, K. Th17 Cells Pathways in Multiple Sclerosis and Neuromyelitis Optica Spectrum Disorders: Pathophysiological and Therapeutic Implications. Mediators Inflamm. 2016, 5314541 (2016). 
${ }^{[107]}$ Lawrence Steinman, M. D. Multiple Sclerosis: A Coordinated Immunological Attack against Myelin in the Central Nervous System. Cell 85, 299-302 (1996).

${ }^{[108]}$ Rostami, A. \& Ciric, B. Role of Th17 cells in the pathogenesis of CNS inflammatory demyelination. J. Neurol. Sci. 333, 76-87 (2013).

${ }^{[109]}$ Stromnes, I. M., Cerretti, L. M., Liggitt, D., Harris, R. A. \& Goverman, J. M. Differential regulation of central nervous system autoimmunity by $\mathrm{T}(\mathrm{H}) 1$ and T(H)17 cells. Nat. Med. 14, 337-342 (2008).

${ }^{[110]}$ Mari, E. R., Rasouli, J., Ciric, B., Moore, J. N., Conejo-Garcia, J. R., Rajasagi, N., Zhang, G. X., Rabinovich, G. A. \& Rostami, A. Galectin-1 is essential for the induction of MOG35-55-based intravenous tolerance in experimental autoimmune encephalomyelitis. Eur. J. Immunol. 46, 1783-1796 (2016).

${ }^{[111]}$ Salama, A. D., Chitnis, T., Imitola, J., Ansari, M. J. I., Akiba, H., Tushima, F., Azuma, M., Yagita, H., Sayegh, M. H. \& Khoury, S. J. Critical role of the programmed death-1 (PD-1) pathway in regulation of experimental autoimmune encephalomyelitis. J. Exp. Med. 198, 71-78 (2003).

${ }^{[112]}$ Starossom, S. C., Mascanfroni, I. D., Imitola, J., Cao, L., Raddassi, K., Hernandez, S. F., Bassil, R., Croci, D. O., Cerliani, J. P., Delacour, D., Wang, Y., Elyaman, W., Khoury, S. J. \& Rabinovich, G. A. Galectin-1 Deactivates Classically Activated Microglia and Protects from Inflammation-Induced Neurodegeneration. Immunity 37, 249-263 (2012).

${ }^{[113]}$ Semerano, L., Minichiello, E., Bessis, N. \& Boissier, M. C. Novel Immunotherapeutic Avenues for Rheumatoid Arthritis. Trends Mol. Med. 22, 214-229 (2016).

${ }^{[114]}$ Takayanagi, H., Juji, T., Miyazaki, T., Iizuka, H., Takahashi, T., Isshiki, M., Okada, M., Tanaka, Y., Koshihara, Y., Oda, H., Kurokawa, T., Nakamura, K. \& Tanaka, S. Suppression of arthritic bone destruction by adenovirus-mediated Itextitcsk gene transfer to synoviocytes and osteoclasts. J. Clin. Invest. 104, 137-146 (1999).

${ }^{[115]}$ Rabinovich, G. A. Apoptosis as a target for gene therapy in rheumatoid arthritis. Mem. Inst. Oswaldo Cruz 95, 225233 (2000).

${ }^{[116]}$ Duris, F. H., Fava, R. A. \& Noelle, R. J. Collagen-Induced Arthritis as a Model of Rheumatoid Arthritis. Clin. Immunol. Immunopathol. 73, 11-18 (1994).

${ }^{[117]}$ Xibillé-Friedmann, D., Rivera-Bahena, C. B., Rojas-Serrano, J., Burgos-Vargas, R. \& Montiel Hernández, J.-L. A decrease in galectin-1 (Gal-1) levels correlates with an increase in anti-Gal-1 antibodies at the synovial level in patients with rheumatoid arthritis. Scand. J. Rheumatol. 42, 102-107 (2013).

${ }^{[118]}$ Harjacek, M., Diaz-Cano, S., De Miguel, M., Wolfe, H., Maldonado, C. A. \& Rabinovich, G. A. Expression of galectins-1 and -3 correlates with defective mononuclear cell apoptosis in patients with juvenile idiopathic arthritis. J. Rheumatol. 28, 1914-1922 (2001).

[119] Sartor, R. B. Mechanisms of disease: pathogenesis of Crohn's disease and ulcerative colitis. Nat. Clin. Pract. Gastroenterol. Hepatol. 3, 390-407 (2006).

${ }^{[120]}$ Santucci, L., Fiorucci, S., Rubinstein, N., Mencarelli, A., Palazzetti, B., Federici, B., Rabinovich, G. A. \& Morelli, A. Galectin-1 suppresses experimental colitis in mice. Gastroenterology 124, 1381-1394 (2003).

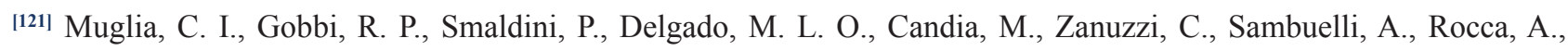
Toscano, M. A., Rabinovich, G. A. \& Docena, G. H. Inflammation Controls Sensitivity of Human and Mouse Intestinal Epithelial Cells to Galectin-1. J. Cell. Physiol. 231, 1575-1585 (2016).

${ }^{[122]}$ Rubio-Tapia, A., Hill, I. D., Kelly, C. P., Calderwood, A. H. \& Murray, J. A. ACG Clinical Guidelines: Diagnosis and Management of Celiac Disease. Off. J. Am. Coll. Gastroenterol. ACG 108, 656-676 (2013).

${ }^{[123]}$ Commodaro, A. G., Bueno, V., Belfort, R. \& Rizzo, L. V. Autoimmune uveitis: The associated proinflammatory molecules and the search for immunoregulation. Autoimmun. Rev. 10, 205-209 (2011).

${ }^{[124]}$ Romero, M. D., Muiño, J. C., Bianco, G. A., Ferrero, M., Juarez, C. P., Luna, J. D. \& Rabinovich, G. A. Circulating anti-galectin-1 antibodies are associated with the severity of ocular disease in autoimmune and infectious uveitis. Investig. Ophthalmol. Vis. Sci. 47, 1550-1556 (2006). 
${ }^{[125]}$ Silva, C. A., Cocuzza, M., Carvalho, J. F. \& Bonfá, E. Diagnosis and classification of autoimmune orchitis. Autoimmun. Rev. 13, 431-434 (2014).

${ }^{[126]}$ Dettin, L., Rubinstein, N., Aoki, A., Rabinovich, G. A. \& Maldonado, C. A. Regulated expression and ultrastructural localization of galectin-1, a proapoptotic $\beta$-galactoside-binding lectin, during spermatogenesis in rat testis. Biol. Reprod. 68, 51-59 (2003).

${ }^{[127]}$ Iglesias, M. M., Rabinovich, G. A., Ivanovic, V., Sotomayor, C. \& Wolfenstein-Todel, C. Galectin-1 from ovine placenta - Amino-acid sequence, physicochemical properties and implications in T-cell death. Eur. J. Biochem. 252, 400-407 (1998).

${ }^{[128]}$ von Wolff, M., Wang, X., Gabius, H. J. \& Strowitzki, T. Galectin fingerprinting in human endometrium and decidua during the menstrual cycle and in early gestation. Mol. Hum. Reprod. 11, 189-194 (2005).

${ }^{[129]}$ Blois, S. M., Ilarregui, J. M., Tometten, M., Garcia, M., Orsal, A. S., Cordo-Russo, R., Toscano, M. A., Bianco, G. A., Kobelt, P., Handjiski, B., Tirado, I., Markert, U. R., Klapp, B. F., Poirier, F., Szekeres-Bartho, J., Rabinovich, G. A. \& Arck, P. C. A pivotal role for galectin-1 in fetomaternal tolerance. Nat. Med. 13, 1450-1457 (2007).

${ }^{[130]}$ Ramhorst, R. E., Giribaldi, L., Fraccaroli, L., Toscano, M. A., Stupirski, J. C., Romero, M. D., Durand, E. S., Rubinstein, N., Blaschitz, A., Sedlmayr, P., Genti-Raimondi, S., Fainboim, L. \& Rabinovich, G. A. Galectin-1 confers immune privilege to human trophoblast: Implications in recurrent fetal loss. Glycobiology 22, 1374-1386 (2012).

${ }^{[131]}$ Vasen, G., Battistone, M.A., Croci, D.O., Brukman, N.G., Weigel Muñoz, M., Stupirski, J.C., Rabinovich, G.A., and Cuasnicú, P.S. The galectin-1-glycan axis controls sperm fertilizing capacity by regulating sperm motility and membrane hyperpolarization. FASEB J 29, 4189-4200 (2015).

${ }^{[132]}$ Freitag, J., Berod, L., Kamradt, T. \& Sparwasser, T. Immunometabolism and autoimmunity. Immunol. Cell Biol. 94, 925-934 (2016).

${ }^{[133]}$ Girotti, M. R., Salatino, M., Dalotto-Moreno, T. \& Rabinovich, G. A. Sweetening the hallmarks of cancer: Galectins as multifunctional mediators of tumor progression. J. Exp. Med. 217, e20182041 (2020).

${ }^{[134]}$ Navarro, P., Martínez-Bosch, N., Blidner, A. G. \& Rabinovich, G. A. Impact of Galectins in Resistance to Anticancer Therapies. Clin. Cancer Res. (2020) doi:10.1158/1078-0432.CCR-18-3870.

${ }^{[135]}$ Cagnoni, A. J., Pérez Sáez, J. M., Rabinovich, G. A. \& Mariño, K. V. Turning-Off Signaling by Siglecs, Selectins, and Galectins: Chemical Inhibition of Glycan-Dependent Interactions in Cancer. Front. Oncol. 6, 109 (2016).

\section{Bios}

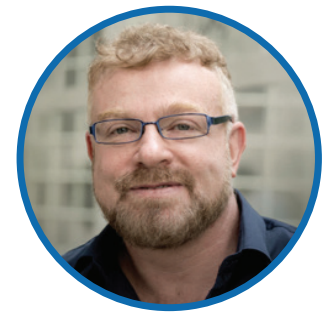

\section{Gabriel Adrián Rabinovich}

Obtained his degree in Biochemistry (1993) and his $\mathrm{PhD}$ in Immunology (1999) from the School of Chemical Sciences at the National University of Córdoba, Argentina. Currently, he is Senior Investigator of CONICET, Head of the Laboratory of Immunopathology at the Institute of Biology and Experimental Medicine and Professor of Immunology at the School of Exact and Natural Sciences, University of Buenos Aires. He is member of several academies including the US National Academy of Sciences and is visiting professor at international universities. He received several awards including the Argentinean Investigator Award and the Guggenheim, Bunge \& Born and Konex Awards.

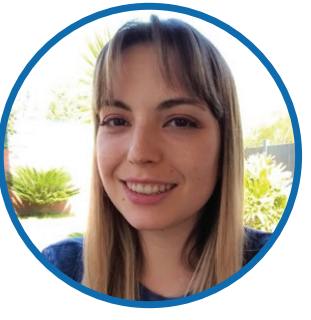

\section{Camila Agustina Bach}

Obtained her degree in Biology (2020) from the University of Buenos Aires and is pursuing a degree to become a Biology Professor. Currently, she is a $\mathrm{PhD}$ student at the Laboratory of Immunopathology at the Institute of Biology and Experimental Medicine and a teaching assistant of Immunochemistry at the University of Buenos Aires. Her research focuses on deciphering the role of the Galectin1-Glycan interactions in resistance to cancer immunotherapeutic modalities, particularly in lung and kidney cancer. 


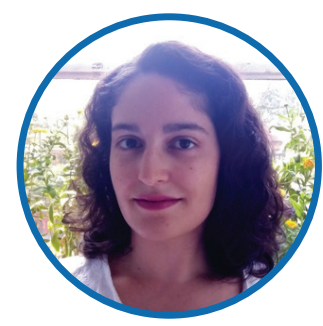

Anabela Cutine

Obtained her degree in Biology (2015) from the University of Buenos Aires and is currently a $\mathrm{PhD}$ student at the Institute of Biology and Experimental Medicine and a teaching assistant of Immunology at Maimonides University. Her research focuses on deciphering the role of B cells, plasma cells and immunoglobulins in intestinal inflammatory diseases from a glycoimmunological perspective.

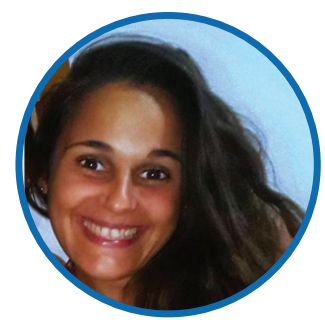

\section{Lorena Laporte}

Obtained her degree in Biochemistry (2013) and completed a Postgraduateresidency in Clinical Microbiology at the Institute of Infectious Diseases (ANLIS Dr Carlos G Malbran) (2018) and is currently a PhD student from the University of Buenos Aires. Her ongoing research is developed at the Immunopathology Lab at the Institute of Biology and Experimental Medicine (IBYME - CONICET). The main goal of her work is to study the role of galectins and glycans in the crosstalk between skin immune system and the host microbiota.

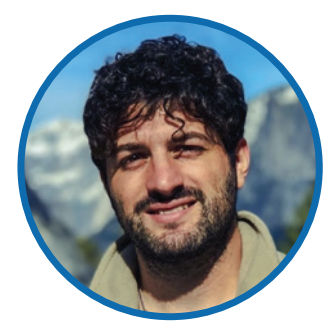

\section{Yamil Damián Mahmoud}

He obtained his degree in Biotechnology (2018) and in Bioinformatics (2020), and is currently a $\mathrm{PhD}$ student from the University of Buenos Aires. Yamil is conducting his research activities at the Translational Immuno Oncology $\mathrm{Lab}$ at the Institute of Biology and Experimental Medicine. His research focuses on the bioinformatic study of biomarkers of response and resistance to immunotherapies and targeted therapies in melanoma using a multidisciplinary approach involving computational biology, genomics, immunology and cancer biology. He aims to identify biomarkers of response to these therapies and the underlying biological mechanisms associated with resistance in order to propose novel therapeutic targets for melanoma patients.

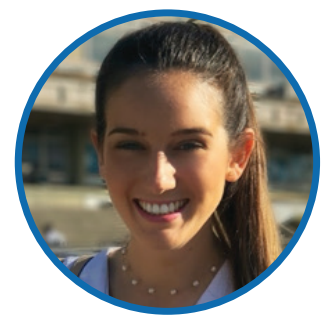

\section{Montana Nicolle Manselle Cocco}

She obtained her degree in Biological Sciences (2018) and is currently a $\mathrm{PhD}$ student from the University of Buenos Aires and is pursuing a degree in Bioinformatics. Her research activities are carried out at the Laboratory of Immunopathology at the Institute of Biology and Experimental Medicine, where she studies the immunomodulatory functions of proto-type galectins and their relevance as a potential immunotherapeutic target in renal cancer. Montana is working at the interface of immunology, cancer biology, immunotherapy and glycobiology using both experimental and bioinformatic approaches. Her main goal is to enhance understanding of the molecular mechanisms underlying response to immunotherapies

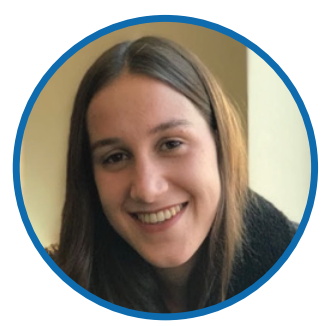

\section{Mora Massaro}

Obtained her degree in Biology (2020) from the National University of Mar del Plata. Mora is currently a $\mathrm{PhD}$ student from the University of Buenos Aires, performing her research activities at the Institute of Biology and Experimental Medicine. Her project is focused on the study of molecular and/or genetic signatures associated with the glycobiological axis in intestinal bowel diseases and colitis-associated colorectal cancer. She aims to identify and validate biomarkers that will allow patient stratification and will eventually contribute for the early detection of colitis-associated colorectal cancer in clinical settings.

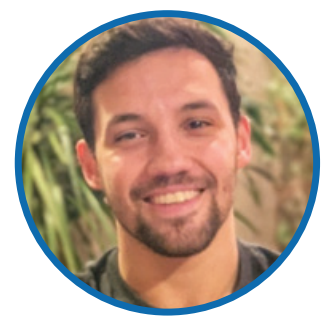

\section{Joaquín Pedro Merlo}

He obtained his degree in Biotechnology (2016) and is pursuing a degreein Bioinformatics. Joaquin is currently a $\mathrm{PhD}$ student at University of Buenos Aires and is doing his research activities at the Translational Immuno Oncology Lab at the Institute of Biology and Experimental Medicine (IBYME-CONICET). His research is focused on the study of biomarkers of response to immunotherapies in melanoma patients. By means of machine learning algorithms and bioinformatic tools, Joaquin aims to study known biomarkers, and propose new ones, in order to obtain new tools for patient diagnosis. 


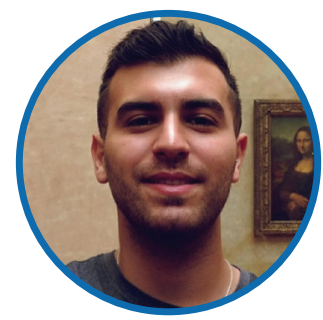

\section{Ramiro Martín Perrotta}

He obtained his bachelor's degree in Biotechnology (2015) from the National University of Quilmes, and is currently a $\mathrm{PhD}$ student at the Immunopathology Lab based at the Institute of Biology and Experimental Medicine (IBYME-CONICET) in Buenos Aires, Argentina. He is pursuing a $\mathrm{PhD}$ in Biological Chemistry from the Faculty of Exact and Natural Sciences at the University of Buenos Aires (FCEN-UBA), planning to graduate in May-June 2021. He received several awards including the FulbrightArgentina scholarship for Future Leaders, the AACR scholar in training award and the AAI trainee abstract award. He works at the interface between oncology and immunology focusing on breast cancer early dissemination and metastasis.

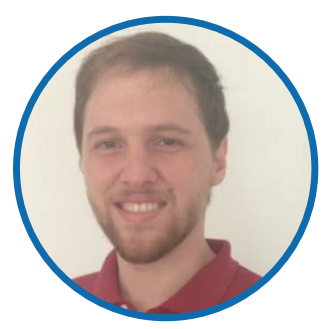

\section{Nicolas Sarbia}

$\mathrm{He}$ obtained his degree in Biochemistry (2016) and is currently a $\mathrm{PhD}$ student from the University of Buenos Aires. He is finishing his doctoral thesis at the Immunopathology Lab at the Institute of Biology and Experimental Medicine, studying the role of galectinglycan interactions in the interaction between triplenegative breast cancer and B lymphocytes. His work may support the use of galectins as target for breast cancer immunotherapy.

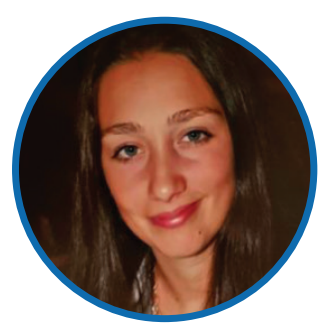

\section{Florencia Veigas}

She obtained her degree in Biotechnology (2017) and is currently a PhD student from the University of Buenos Aires and a teaching assistant at the Argentine University of Enterprise. Florencia is performing her research activities at the Translational Immuno- Oncology $\mathrm{Lab}$ at the Institute of Biology and Experimental Medicine. Her research focuses on the study of the molecular mechanisms underlying resistance to immunotherapy and targeted therapy in melanoma using a multidisciplinary approach involving immunology, cancer biology and bioinformatics. She aims to identify predictive biomarkers of response and propose novel therapeutic strategies to enhance patients' outcomes and overcome resistance mechanisms. 